University of Rhode Island

DigitalCommons@URI

Open Access Master's Theses

1990

\title{
Testing of the Physical Self-Perception Profile with a Middle-Aged Adult Population
}

Elias D. Speliotis

University of Rhode Island

Follow this and additional works at: https://digitalcommons.uri.edu/theses

\section{Recommended Citation}

Speliotis, Elias D., "Testing of the Physical Self-Perception Profile with a Middle-Aged Adult Population" (1990). Open Access Master's Theses. Paper 1646.

https://digitalcommons.uri.edu/theses/1646

This Thesis is brought to you for free and open access by DigitalCommons@URI. It has been accepted for inclusion in Open Access Master's Theses by an authorized administrator of DigitalCommons@URI. For more information, please contact digitalcommons-group@uri.edu. 


\section{TESTING OF THE PHYSICAL SELF-PERCEPTION}

PROFILE WITH A MIDDLE-AGED

ADULT POPULATION

BY

ELIAS D. SPELIOTIS

A THESIS SUBMITTED IN PARTIAL FULFILLMENT OF THE REQUIREMENTS FOR THE DEGREE OF

MASTER OF SCIENCE

IN

PHYSICAL EDUCATION

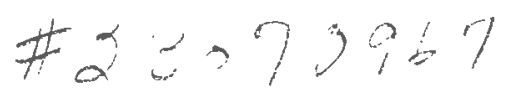

UNIVERSITY OF RHODE ISLAND 


\section{ABSTRACT}

This study was conducted to examine relationships among specific physical self-perceptions, a more general physical self-worth, and global self-esteem in an adult population between the ages of 30 and 65. Adults from several intact groups $(N=260)$ were given the Physical Self-Perception Profile(PSPP) (Fox and Corbin, 1989), Rosenberg's Self-Esteem Inventory(SEI) (Rosenberg, 1965), and several exercise history questions(Fernhall and Ausmus, 1987). The subjects were selected from members of the Saint Nicholas Greek Orthodox Church community in Lexington, Massachusetts; members of the YMCA in Melrose, Massachusetts; employees of Coldwell Banker Realtors, North Kingstown, Rhode Island; members of the Adult Fitness Program at the University of Rhode Island, Kingston, Rhode Island; and members of the Senior Swim Class, at the University of Rhode Island, Kingston, Rhode Island.

Scale structure, relationships, and criterion validity were determined for the specific physical self-perceptions, physical self-worth, and global self-esteem. The coefficients between physical self-worth and the four self-perceptions/r's between .785 and .548 for females; r's between .798 and .623 for males) were significantly greater $(p<.05)$ than the coefficients between the specific self-perceptions and global self-esteem(r's of between .564 and .247 for females: r's of between .544 and .316 for males). The factor analysis 
exhibited overlapping between physical self-worth and attractive body, but the four specific self-perceptions were shown to be independent.

The PSPP scales were found to have good criterion validity. The physical condition subscale had the best convergent validity with physical activity of all the subscales. The Physical Self-Perception Profile(PSPP) was able to significantly $(p<.001)$ discriminate between exercisers and non-exercisers. Using discriminant function analysis a total of $84.56 \%$ of all female subjects were properly classified, while a total of $78.38 \%$ of all male subjects were properly. It was also determined that condition(p<.00I) and strength $(\mathrm{p}<.02)$ were the only subscales which significantly distinguished between subjects who participated in an organized fitness program and those who did not participate.

The four specific physical self-perception scales of the PSPP were found to be valid, and independent. However, the physical self-worth scale was found to be interdependent with the attractive body scale. This questions the ability of the physical self-worth scale to act as a mediating variable, and has also led to the recommendation that the scale not be utilized in conjunction with the specific self-perception scales until it is shown to be truly independent. 


\section{Acknowledgements}

I would like to thank Dr. Sonstroem, and the other committee members for their time, effort, and suggestions in this study. I would also like to thank my parents and family for their support. Finally, I owe my deepest appreciation, and love to Mary who was always there throughout the whole process. Thank you all. 


\section{Table of contents}

Chapter

Page

Abstract

Acknowledgements

Table of contents

List of Tables

ii

iv

$\mathrm{v}$

vi

1. INTRODUCTION

Statement of the Problem

1

Specific Hypotheses

Justification and Significance

Limitations of study

Definitions of Terms

4

6

7

8

9

2. Review of Literature

10

Problems in Past Self-Esteem

Research

10

Clarification of Terminology

11

Self-Esteem Models

13

Exercise and Self-Esteem

20

The Physical Self-Perception

Profile

24

3. Methodology

subjects

39

Instruments

42

Statistical Analyses

4. Results and Discussion

Scale structure and Relationships

Criterion Validity

Discussion

81

Practical Applications

87

Implications for Future Research

References

Appendix A

94

Appendix B

96

Appendix C

98

Bibliography 
2 Scale Internal Consistencies:

Cronbach Alphas

3 Zero-Order Correlation Coefficients

Among Self-Perception Variables

4 Comparison of Subscale Coefficients with Physical Self-Worth and Global Self-Esteem

5 Comparison of Zero-Order and Partial Correlation Coefficients Controlling

for Physical Self-Worth

Exploratory Factor Analysis - Females Principal Component Analysis - Varimax Rotation

Exploratory Factor Analysis - Males Principal Component Analysis - Varimax Rotation

Means and Standard Deviations:

Exercisers versus Non-Exercisers (Female)

Subject Classification: Exercisers versus Non-Exercisers(Females)

Means and Standard Deviations: Exercisers versus Non-Exercisers (Males)

11 Subject Classification: Exercisers versus Non-Exercisers(Males)

12 Extent of Participation: From Low to High Active - Females

13 Subject Classification: From Low to High Active - Females

14 Extent of Participation: From Low to High Active - Males 
15 Subject Classification: From Low to High Active - Males

16

Summary of ANCOVA Testing: Means

for Significant Group and Sex Effects 


\section{Introduction}

The past thirty years have brought a renewed interest in self-esteem(Harter, 1986). Although the majority of such studies have occurred in the academic realm, physical educators have become increasingly more interested in the relationship between exercise and self-esteem(Fox, 1988a; Sonstroem, 1984). Previous research has attempted to understand what self-esteem consists of, while also examining what can make it change. Recently there is growing discontent with this research because of a variety of problems that have existed(Harter, 1986; Sonstroem, 1984). There have been problems in definitions of terminology, development of theoretical models, as well as flaws in the statistical testing of the constructs(Dishman, 1978; Harter, 1986; Sonstroem, 1984). Learning from these mistakes, psychologists have attempted to develop models that use uniformly agreed upon definitions, and that can be validly tested and reproduced(Shavelson, Hubner, and Stanton, 1976; Harter, 1982; Fox and Corbin, 1989; Sonstroem and Morgan, 1989).

One model designed by Shavelson, et al.(1976), was developed after the review of many different self-esteem studies within the educational field. The Shavelson model theorizes that self-concept has a hierarchical structure. At the apex is global self-esteem. The next level below is 
divided into academic and nonacademic self-concepts. Then below academic self-concept are the specific self-perceptions within that setting. This breakdown occurs on the nonacademic side also, with this side being divided into social and physical self-worth, and then more specific selfperceptions(Shavelson, et al., 1976).

Shavelson, et al.(1976) also believe that self-esteem is multidimensional. For example, in the academic setting, experiences within different classes will lead to the development of an academic self-concept which in turn will influence one's global self-esteem. Since the model was introduced there has been a keen interest in testing the models plausibility. Several studies have found that the Shavelson model is verifiable and the results reproducible, however these studies show that the hierarchy may be more complex than originally theorized(Fleming and Watts, 1980; Marsh and Shavelson, 1985; Byrne and Shavelson, 1986).

One study that has taken the Shavelson model one step further was completed by Harter(1982). This author not only attempted to test the Shavelson model, but designed an inventory which could be used with children between third and sixth grade. The Children's Self-Perception Profile was designed to test the hierarchical and multidimensional structure of self-concept. Harter(1982) has been able to show that, in fact, children as young as eight years old have the ability to distinguish between activities and then classify 
them as to their effect on their self-concept.

Physical educators and sport psychologists have been interested in the relationship between exercise and selfesteem for many years. Fox and Corbin(1989), in an attempt to further the understanding of this relationship developed the Physical Self-Perception Profile(PSPP). The authors used an open-ended questionnaire for initial scale development, and the "structure alternative format" question design, similar to the methodology Harter(1982) used in the formation of the Perceived Competence Scale for children. Fox and Corbin(1989) attempted to determine those specific physical selfperceptions young adults believe to be the most important in physical competence. By analyzing past research on selfesteem and exercise, and the responses to the open-ended questions which were given to a small sample of college students, Fox and Corbin(1989) were able to establish four specific physical self-perception categories. The four most prevalent self-perception groupings were sports competence, physical conditioning, attractive body, and physical strength and musculature.

Fox and Corbin(1989) were able to show that the physical domain is hierarchical in structure(Appendix A). They showed that the specific physical self-perceptions are not directly related to global self-esteem. Instead there is an intermediary domain of a more general physical self-worth. This component consists of overall feelings about the physical 
self. To complete the hierarchy, physical self-worth is related to global self-esteem. This is the most recent model to be developed that includes specific facets of physical self-esteem. Previously, models had evaluated how physical activity related to self-esteem or how self-esteem changed with the introduction of exercise(Brown, Morrow and Livingston, 1982; Fox, Corbin and Couldry, 1985; Neale, Sonstroem and Metz, 1969; Safrit, Wood and Dishman, 1985; Sonstroem, 1982; Sonstroem and Morgan, 1989; Young, 1985).

The majority of self-esteem research has used subjects ranging from young children up to young adults. There are very few studies that have evaluated an older adult population. Because many studies have investigated selfesteem and education it is understandable why school aged children are used. Similarly, for physical educators it has been more convenient to use children or young adults, as they are already in predetermined groups. Unfortunately, these research techniques neglect the large population of older adults.

\section{Statement of the Problem}

The purpose of this study was to examine relationships among specific physical self-perceptions, a more general physical self-worth and global self-esteem in an older adult population. A sample of adults between the ages of thirty 
and sixty-five, from several intact groups were given the PSPP(FOx and Corbin, 1989), Rosenberg's Self-Esteem Inventory(SEI) (Rosenberg, 1965), and several questions assessing personal exercise habits. The subjects included members of the Saint Nicholas church community in Lexington, Massachusetts; members of the YMCA in Melrose, Massachusetts; employees of Coldwell Banker Realtors, North Kingstown, Rhode Island; members of the Adult Fitness program at the University of Rhode Island; and members of the Adult Swim program at the University of Rhode Island.

The results were visually compared to the results of the original validation study of the PSPP(Fox and Corbin, 1989). This latter study found that there was a hierarchical progression in self-perceptions beginning with the specific physical self-perceptions, then moving to the more general physical self-worth and ending with global self-esteem(Fox and Corbin, 1989). Fox and Corbin(1989) were also able to show that the physical self-concept was multidimensional in that each of the four specific physical self-perceptions were independent factors in the model.

Statistical analysis was completed to determine whether older adults would have similar results as those found in the study completed by Fox and Corbin(1989). All analyses were completed separately by sex. Scale structures and relationships were first determined. This included descriptive statistics, including mean, standard deviation, 
range, skewness, and kurtosis for the subscales and scales. Internal consistencies for all subscales and scales were also calculated with Cronbach's coefficient alpha. Then the relationships between scales was examined by calculating Pearson $\mathrm{r}^{\prime} \mathrm{s}$, both at the zero-order and when controlling Physical self-worth. The final analysis testing scale structure was exploratory factor analysis. This analysis included all five components of the PSPP. Determination of the appropriate number of components were completed by both the parallel analysis method, and the minimum average partial(MAP) analysis. Criterion validity, which concerns itself with convergent and discriminant validity, was then calculated. Three different analyses were completed. First, subjects were divided simply by whether they exercised or not. The second analysis was determined by the extent of participation. The final analysis was between members of an organized fitness group and non-membership.

\section{Specific Hypotheses}

1. Physical self-worth will be significantly related to global self-esteem.

2. The specific physical self-perception components of sports competence, physical conditioning, attractive body, and physical strength and musculature will be more highly related to physical self-worth than to global self-esteem.

3. The Physical Self-Perception Profile scales will 
significantly predict levels of physical activity reported by subjects.

\section{Justification and Significance}

Physical educators have been interested in the relationship between exercise and self-esteem for many years. Recently, however, it has been found that many of the past studies have been deficient in many areas. These problems include lack of theoretically sound models, inadequate sample size, poor sample selection, and weak statistical results(Sonstroem, 1984). These problems have led to poor reproducability of past research.

The PSPP developed by Fox and Corbin(1989) is the most recent attempt at the development of a specific inventory for the physical realm of self-esteem, that follows an established model(Appendix A). The PSPP(Fox and Corbin, 1989) has received initial statistical support for validity and reliability in a population of college students. The present study represented an attempt to replicate Fox and Corbin's(1989) results in an older population. The population was adults between the ages of thirty and sixty-five. This population was chosen because of the lack of research on this group. Additionally, the focus of cardiac rehabilitation programs and many adult fitness programs is on people in this age range. The majority of research completed on self-esteem has been with people ranging in age between eight and twenty- 
one years old. This population is popular to study for two reasons. One being that they are easily accessible and testable. The other is that self-esteem formation is thought to be most capable of influence in that age span(Harter, $1983)$.

In the analysis of self-esteem, especially in the physical realm, older adult evaluation is becoming more important. Adults continually enter and participate in exercise programs, and just as quickly a large number dropout(Gale, Eckhoft, Mogel, and Rodnick, 1984; Dishman, Sallis and Orenstein, 1985). One topic that is overlooked when examining adults' participation in fitness programs is what facets of physical activity play an important role in people feeling good about themselves(Dishman, Sallis, and Orenstein, 1985). The PSPP may help give a clearer picture of these factors. This research is important in that it will help determine the potential of the PSPP. The results hopefully will offer new insight not only into the self-esteem and exercise relationships, but, also, may introduce new information on an infrequently studied population.

\section{Limitations of the Study}

1. The responses to the inventory were limited to volunteers willing to participate. This was not a random sample of the adult population between the ages of thirty and sixty-five. 2. The population used was a predominantly church-oriented, 
upper-middle class, professional population. This population did not include all sub-groups of an adult population.

\section{Definition of Terms}

Self-concept - "In our view, the self-concept is the totality of the individual's thoughts and feelings with reference to himself or herself as an object"(Rosenberg and Kaplan, 1982, p. xiii).

Global self-esteem - "Self-esteem, as noted, is a positive or negative attitude toward a particular object, namely, the self" (Rosenberg, 1965, p. 30). The evaluative component of self-concept(Gergen, 1971).

Physical-Competence - "a general evaluation of the self as possessing overall physical fitness"(Sonstroem and Morgan, 1989 ).

Self-perception - how one thinks or feels others think or feel about them. "It is thus not others' attitudes toward us but our perception of their attitudes that is critical for selfconcept formation"(Rosenberg, 1979, p. 65). 


\section{CHAPTER 2}

\section{Review of Literature}

The review of the literature is divided into five sections. These are: (a) Problems in past self-esteem research, (b) Clarification of terminology, (c) Self-esteem models, (d) Exercise and self-esteem, and (e) The physical self-perception profile. Within these five sections there are several subsections.

\section{Problems in Past Self-Esteem Research}

Self-esteem has become one of the more challenging topics in psychology today(Harter, 1986) There have been many different studies completed in attempts to understand what self-esteem is, and what is included in the structure of selfesteem. In early research it was assumed that self-esteem was unidimensional, hence studies attempted to measure selfesteem to fit this model(Rosenberg, 1979; Harter, 1986). Recently, however, it has become clear that not only is the unidimensional model incorrect, but that many previous studies have been experimentally and statistically incorrect(Dishman, 1978; Fleming and Courtney, 1984; Harter, 1986; Marsh, 1987; Shavelson, Hubner and Stanton, 1976; Sonstroem, 1984). These inconsistencies in past research have lead many psychologists to question the validity and reliability of these studies(Sonstroem, 1984). Several of the problems that exist 
in these studies include: lack of a control group, an inability to reproduce the study, poorly validated questionnaires, and an over generalization of the results from the subject population to the general population(Sonstroem, 1984). Because of these problems in past research psychologists have been attempting to offer a better and clearer understanding of self-esteem. As Rosenberg resolves "we are persuaded that until a reasonably clear idea of what the self-concept includes is gained, progress in self-concept research will be seriously impeded"(Rosenberg, 1979, p. 3).

\section{Clarification of Terminology}

One of the major problems with self-esteem research has been the lack of clear and concise definitions of the terminology. Two terms that have been used interchangeably are self-concept and self-esteem. Unfortunately, in much of the past research authors have used their own definitions (Shavelson, Hubner and Stanton, 1976). Researchers only recently have realized the importance of having universal definitions for both self-esteem and self-concept.

Self-concept is the descriptive process through which a person develops a picture of him or herself(Gecas and Mortimer, 1987; Rosenberg, 1979; Anderson, 1981; Combs, 1981). Rosenberg and Kaplan(1982) expand on the definition by saying "In our view, the self-concept is the totality of the individual's thoughts and feelings with reference to himself 
or herself as an object"(p. xiii). Self-esteem carries an evaluative element by which people measure their selfworth(Rosenberg, 1965; Gecas and Mortimer, 1987; Gergen, 1971). Rosenberg and Kaplan(1982) offer this definition "Self-esteem refers to whether one accepts oneself, respects oneself, considers oneself a person of worth"(p. 4).

Self-concept and self-esteem have been used interchangeably because although they are two separate concepts, self-esteem is actually an important part of selfconcept. Shavelson, et al.(1976) explain that individuals are not only able to create an image of themselves in a variety of situations, but that each person is also able to evaluate themselves under those circumstances. As selfconcept develops, individuals will use the evaluative component, self-esteem, to help in the continued development and maintenance of their self-concept(Rosenberg, 1979).

Most of the current self-esteem researchers have accepted these definitions of self-esteem and self-concept (Byrne and Shavelson, 1986; Harter, 1983; Marsh and Shavelson, 1985). They have also realized that by agreeing upon these definitions the first step in the attempt to better understand self-esteem has been completed. Although the definitions for self-esteem and self-concept have been more clearly defined and accepted, the model for self-esteem structure is far from being agreed upon. 


\section{Self-Esteem Models}

Unidimensional Model of SelE-Esteem

One theory that has pervaded much of the past research is that self-esteem is unidimensional(Fleming and courtney, 1984; Fox, 1988a; Fox, 1988b; Harter, 1986). Psychologists believing that self-esteem was unidimensional developed inventories that measured feelings of success or failure over a wide variety of situations and activities. These questionnaires scored each question and simply summed the scores to determine a person's global self-esteem(Fox, 1988b; Harter, 1986; Rosenberg, 1979).

This hypothesis of self-esteem has received criticism for an assortment of problems(Harter, 1983; Rosenberg, 1979). The main problem with the unidimensional model is that it "ignores the specific content of the items included under the assumption that one's total score will adequately reflect one's sense of self across the variety of domains in one's life"(Harter, 1986, p. 139). Rosenberg(1979) believes that by simply adding up one's score the psychologist is neglecting the idea that a person's self-esteem develops through a complex analysis of many different variables which an individual may experience. Fox(1988a) also criticizes the unidimensional model by stating that people in a variety of situations will feel differently in each circumstance, and these different feelings may all have a varying amount of influence on global self-esteem for each person. 
Although the unidimensional model has been criticized, it is believed that global self-esteem is important. Rosenberg(1979) defends the need to examine both global selfesteem and the specific elements. He explains that "both exist within the individual's phenomenal field as separate and distinguishable entities, and each can and should be studied in its own right"(Rosenberg, 1979, p. 20). Rosenberg(1979) also explains that it is impossible to summarize from the specific to the general, or from the general to the specific. The recognition that there is a global component as well as more specific features of self-esteem, challenges the argument for the unidimensional model. Thus, it has become necessary to take a different approach to self-esteem research.

\section{Multidimensional and Hierarchical Model of Self-Esteem}

A newer model that has received much attention was introduced by Shavelson, Hubner and Stanton(1976). Their model was developed after a careful review of self-esteem research. This paradigm has moved away from the unidimensional approach and has attempted to evaluate the more complex structure of one's self-esteem. Shavelson, Hubner and Stanton(1976) theorize that self-concept has seven features. They explain that self-concept is: organized, multifaceted, hierarchical, stable, developmental, evaluative, and differentiable(Shavelson, et al., 1976). All seven facets are important in the understanding of self-concept, although 
the multidimensional and hierarchical components are the two that have received the most attention.

First, it is believed that self-concept is organized. The experiences a person goes through are both numerous and complex. Because of this, it is necessary for every individual to categorize these events, thus making one's selfconcept ordered(Shavelson, et al., 1976).

Shavelson, et al.(1976) also theorized that general selfconcept is stable. However, as one moves down the selfconcept hierarchy the specific self-perceptions are increasingly transient and more susceptible to influences from the environment. The authors explain that this increased instability is due to the fact that an individuals' selfconcept is different for every situation they encounter(Shavelson, et al., 1976, p. 414).

Another trait of self-concept is that it is developmental. Shavelson, et al.(1976) assert that children only have a global self-concept. However, as they mature, people are able to think abstractly which helps in the arrangement and classification of situations(Shavelson, et al., 1976).

A fourth characteristic of self-concept, according to Shavelson, et al.(1976), is that it is evaluative. They believe that not only does a person have a picture of themselves in a certain situation, but that these pictures have personal meaning and importance to people(Shavelson, 
et al., 1976). The authors explain that "The evaluative dimension can vary in importance for different individuals and also for different situations"(Shavelson, et al., 1976, p. 414$)$.

A fifth attribute of self-concept is that each division is separate and distinguishable from other sections, although they may be related hypothetically (Shavelson, et al., 1976). It is thought that specific self-perceptions within a field will be more closely related to each other than across domains(Shavelson, et al., 1976). For example, physical selfconcept should be more highly related to physical competence than to any aspect of academic self-concept.

The five properties mentioned above are all important in the understanding of self-concept, however the multifaceted and hierarchical properties have received the most attention in recent research. Shavelson, et al.(1976) theorize that self-esteem is multifaceted, which is due to the wide variety of experiences and hence categories which exist. These categories are thought to include experiences related to school, physical appearance, physical competence, and social acceptance(Shavelson, et al., 1976).

The Shavelson model also proposes that the multiple categories fall into a hierarchy. They begin with global self-esteem at the apex of the hierarchy. The next level is divided into academic and nonacademic self-concepts. The model then has subareas of the self-concepts, and then 
evaluations of behavior in specific situations(Shavelson, et al., 1976). The Shavelson model has attempted to develop a paradigm for self-concept which incorporates all the different theories that had been previously developed.

\section{Analysis of Multidimensional Research}

Since its introduction the Shavelson model has received statistical support, and has also led to renewed interest in the construct of self-esteem. Fleming and Watts(1980) tested the model with college-aged adults. The students were given a questionnaire which was developed by modifying the Janis and Field Feelings of Inadequacy Scale(Fleming and Watts, 1980). They used one hundred and six sophomores, and through principle component analysis, and the calculation of correlation coefficients it was determined that the items of the Janis and Field inventory loaded onto similar factors as proposed by Shavelson, Hubner and Stanton(1976). These results substantiated the theory that self-esteem is multidimensional(Fleming and Watts, 1980). It was also shown that there is support for a hierarchical split between academic and non-academic domains(Fleming and watts, 1980).

In a follow-up study, Fleming and Courtney(1984) tried to replicate the Fleming and Watts' study. They used students in a first year psychology class and found that "our analyses have provided increased support for a hierarchical interpretation of self-esteem and to a modest extent have 
addressed the equivalence of measures problem, at least for college-aged people"(Fleming and Courtney, 1984, p. 418). Fleming and Courtney(1984) conclude that the Shavelson model may not be the ultimate self-esteem model, but that to date it is the best presented and that their study offers the model some statistical support.

Several other studies have also tested the Shavelson model in an attempt to verify the structure of selfconcept(Shavelson and Bolus, 1982; Marsh and Shavelson, 1985; Byrne and Shavelson, 1986). The Shavelson and Bolus(1982) study tried to test the theory that self-concept is multifaceted and hierarchical and that it becomes more stable as one moves up the hierarchy. To test for the hierarchy the authors decided to examine the relationship between general self-concept, academic self-concept, and subject specific self-concepts(Shavelson and Bolus, 1982). The study was able to demonstrate that a hierarchy does indeed exist. For a hierarchy to exist the correlation between general selfconcept and academic self-concept should be greater than the correlations between the subject-matter specific self-concepts and general self-concept(Shavelson and Bolus, 1982). The authors were able to show this relationship not only once but also a second time after a four month period.

Shavelson and Bolus(1982) were also able to confirm that self-concept is multifaceted. The authors found that general self-concept is distinct but related to academic self-concept. 
Shavelson and Bolus(1982) also determined that the subjectmatter's specific facets are separate components, but are related to academic and general self-concept(Shavelson and Bolus, 1982).

Though the study was able to show that self-concept is hierarchical and multidimensional, it was not as successful in proving stability. The authors had hypothesized that as one moves up the hierarchy stability over time would increase. However, it was found that although global self-esteem was the most stable, there was no noticeable difference in stability between general academic self-concept and subject specific self-concept(Shavelson and Bolus, 1982). These results support the theory that self-concept has a multidimensional and hierarchical structure. However, more research into the stability hypothesis is needed before any conclusions can be made.

Marsh and Shavelson(1985) had similar success in proving the multidimensionality of self-concept. However, one result that differed from the Shavelson and Bolus(1982) study was that there appeared to be distinct self-concepts for the subject specific categories of English and Math. This suggests that the academic self-concept may need to be broken down into even smaller more specific categories instead of one all encompassing category as originally theorized(Marsh and Shavelson, 1985).

The Byrne and Shavelson(1986) study was also able to 
present support for the multidimensional and hierarchical construct of self-concept. Byrne and Shavelson(1986) determined that self-concept falls into a hierarchy with general self-esteem at the top, academic self-concept in the middle, and subject-specific self-esteem at the base. Byrne and Shavelson(1986) were able to determine that mathematics and English self-concepts are highly correlated to the academic self-concept. Although this is different from the results of the Marsh and Shavelson(1985) study, Byrne and Shavelson(1986) resolved that the results from both studies showed that self-concepts in both English and mathematics contributed to a general academic self-concept. The authors did explain that each facet and it's impact on the general academic self-concept is independent from the other(Byrne and Shavelson, 1986).

All of these studies offer initial support for the Shavelson model, which was developed from reviewing previous studies and did not offer any statistical support originally. Many of the authors agree that more research is needed, and that in fact self-concept may be more complex than the Shavelson model suggests(Shavelson and Bolus, 1984; Marsh and Shavelson, 1985; Byrne and Shavelson, 1986).

\section{Exercise and Self-Esteem}

\section{Research Examining Exercise and Self-Esteem}

One field that has a great interest in self-esteem theory 
is the field of sport psychology. Although most of the newer developments in self-esteem have been completed in the educational field, physical educators have continued working on their own self-esteem research(Brown, Morrow, and Livingston, 1982; Dishman, 1978; Fox, 1988b; Fox, Corbin and Couldry, 1985; Leonardson, 1977; Sonstroem and Morgan, 1989). There are two areas of self-esteem research that sport psychologists have been especially interested in. The first is the relationship between exercise and self-esteem(Fox, Corbin, and Couldry, 1985; Leonardson, 1977; Leonardson and Gargiulo, 1978; Neale, Sonstroem and Metz, 1969; Safrit, Wood and Dishman, 1985; Sonstroem, 1978, 1982; Thornton, Ryckman, Robbins, Donolli, and Biser, 1977; Young, 1985). The second field of interest for researchers is how self-esteem changes due to a change in exercise habits(Brown, Morrow and Livingston, 1982; Sonstroem, 1984; Sonstroem and Morgan, $1989)$.

The Physical Estimation and Attraction Scale

One inventory that has been used frequently is the Physical Estimation and Attraction Scale(PEAS)(Sonstroem, 1974). The PEAS has been used to study how physical activity is related to self-esteem(Dishman, 1978; Fox, Corbin and Couldry, 1985; Neale, Sonstroem and Metz, 1969; Safrit, Wood and Dishman, 1985; Sonstroem, 1974; Sonstroem, 1976). The inventory examines two factors. One is an individual's 
estimation of their own physical abilities, the second is an individual's attraction to specific physical activities(Sonstroem, 1974). Both Neale, Sonstroem and Metz(1969), and Sonstroem(1974, 1978) found that the estimation component correlates strongly with self-concept, and physical fitness, while physical fitness, itself, is not related to global self-esteem across people. These results have continued to receive statistical support, not only with males but also with females(Dishman, 1978; Fox, Corbin and Couldry, 1985; Safrit, Wood and Dishman, 1985).

Safrit, Wood and Dishman(1985) tested the PEAS with a young adult population. They found that there was a strong estimation factor for both males and females. However, the attraction factor was found to be significant only for the female population(Safrit, Wood and Dishman, 1985). The authors conclude that the PEAS is a strong inventory for measuring physical estimation, but that it would need modification to improve the measurement of attraction (Safrit, Wood and Dishman, 1985). Other studies have also been able to offer statistical support for the relationship between the estimation factor and self-esteem(Fox, Corbin, and couldry, 1985; Dishman, 1978; Sonstroem, 1976).

\section{Other Research in Exercise and Self-Esteem}

Leonardson(1977), and Leonardson and Gargiulo(1978) have also completed studies which have examined the relationship 
between physical fitness and self-esteem. Leonardson(1977) tried to determine whether perceived physical fitness was related to self-concept. He tested both high school students and college freshman. From his research Leonardson(1977) was able to conclude that there was a correlation between perceived physical fitness and self-concept. He also explained that further research between perceived and actual physical fitness would prove beneficial for self-concept research(Leonardson, 1977).

In a follow-up pilot study, Leonardson and Gargiulo(1978) examined the relationship between self-concept, and actual and perceived physical fitness in college freshmen. The study showed that there was a significant correlation between perceived physical fitness and self-concept, but that the relationship between actual physical fitness and self-concept was not statistically significant(Leonardson and Gargiulo, 1978). These two studies support the theory that perceived competence is more highly related to self-esteem than is actual ability. This substantiates the results of the numerous studies utilizing the PEAS inventory, where it has been found that physical estimation is highly related to selfconcept(Fox, Corbin and Couldry, 1985; Neale, Sonstroem and Metz, 1969; Safrit, Wood and Dishman, 1985; Sonstroem, 1974; Sonstroem, 1976). However, all of the above mentioned studies agree that more research is required before any definite conclusions can be made about the relationship between 
physical activity and self-concept.

\section{The Exercise and Self-Esteem Model}

One model that has been recently developed attempts to take the Shavelson model and explain how self-esteem changes through exercise(Sonstroem and Morgan, 1989). This model is "vertically arranged in degrees of increasing situational generality starting from physical self-efficacy at the base of the figure to global self-esteem at the top of the hierarchy"(Sonstroem and Morgan, 1989, p. 332). The authors explain that the lower level factors are components of higher level factors, and that if a change occurs at the lower level it will influence changes in the higher levels(Sonstroem and Morgan, 1989). The model also includes a horizontal component, time. This aspect of the model allows it to examine the manner in which self-esteem changes because of participation in an exercise program(Sonstroem and Morgan, $1989)$.

\section{The Physical Self-Perception Profile}

Psychologists who have tested the Shavelson model have usually examined the academic side of the model(Fleming and Watts, 1980; Fleming and Courtney, 1984; Harter, 1982; Marsh, 1987; Marsh and Shavelson, 1985; Shavelson and Bolus, 1982). Although physical educators have a keen interest in selfesteem research very few models have been developed using 
hierarchical levels of self-perceptions. The Sonstroem and Morgan(1989) model has attempted to use the newer theories to analyze the interaction between self-esteem and exercise.

As for the construct of self-esteem in the physical realm, many recommendations for inventory development utilizing the hierarchical theory have been made, however, the PSPP(FOx and Corbin, 1989) is the most inclusive inventory to be designed. The authors have been able to show the multidimensionality of the physical self, using scales that measure specific physical self-perceptions with high internal validity, and they designed a scale to measure the more general component of physical self-worth.

In designing their model, Fox and Corbin(1989) used the Shavelson model as a theoretical foundation and incorporated several of Harter's(1982) ideas from her development of the Perceived Competence Scale for Children. As Fox and Corbin(1989) explain their goal was to develop a valid physical self-perception inventory, patterned after Harter's Perceived Competence Scale, and that "(a) reflects salient self-perception content, and (b) allows a test of dimensionality and hierarchical structuring"(p. 4ll). The authors contend that with the development of such a questionnaire, one would not only be able to test a variety of factors thought important in the development of the physical self, but also to test the interaction between selfesteem and exercise over time(Fox and Corbin, 1989). 


\section{Harter's Inventory Development}

Harter(1982) attempted to develop an inventory that would evaluate the self-concept of children. The Perceived Competence scale tried to cover all areas important in the development of self-concept. These domains included the cognitive, social and physical areas of growth. Harter(1982) also attempted to measure the development of a child's selfworth. She wanted her inventory to be properly written so that the results would be statistically acceptable, and socially desirable responses would be avoided(Harter, 1982). The domains that Harter tested were determined through observation, past research and interviews with grade school children(Harter, 1982).

The study hypothesized that children over the age of 8 are able to make independent analyses of their abilities in different situations(Harter, 1982). Harter(1982) also theorized that by that age children have a picture of their general self-worth, which is separate from their perceptions in regard to specific situations. These hypotheses emphasize "the hierarchical nature of the self-evaluative process whereby self-esteem or self-worth is viewed as a superordinate construct and competence judgments represent one type of lower-order evaluative dimension"(Harter, 1982). As for the question format, Harter(1982) desired one that protected from socially desirable responses. She designed the questionnaire using a structured alternative format(Harter, 
1982). This format offers the respondent four options, forcing the individual to place themselves within a category, however, none of the responses require the child to answer in the negative(Harter, 1982).

Approximately 300 third through sixth grade children were initially tested. Then 133 nine to twelve year-old children were tested to determine the factorial validity of the questionnaire. Then approximately 2300 other school children from the third to ninth grades were given the inventory to test for replication(Harter, 1982). The results indicated that children are able to differentiate between cognitive, social, and physical competence and general self-worth. It was also shown that the structured alternative format was able to limit the children from giving socially desirable responses(Harter, 1982). Harter(1982) also demonstrated that the questionnaire can be used with children through the ninth grade. She warned, however, that junior high school children may have other self-perception domains which influence their self-worth but were not tapped by this inventorylHarter, 1982). Harter's success in developing such an inventory has further increased interest in self-esteem research.

The PSPP Inventory Development

Fox and Corbin(1989) developed a questionnaire which unites the aspects of the shavelson model with several features from Harter's Perceived Competence Scale. They 
attempted to develop an instrument that would simultaneously measure many different aspects of the physical domain. The introduction of a new questionnaire was necessary, especially in the physical realm of self-esteem. The authors believed that such an instrument would help in the understanding of the relationship between self-esteem and exercise(Fox and Corbin, 1989). These advancements have become especially important with the changes that have been made in self-esteem theory and research.

The study was divided into four phases, with the first two phases primarily concerned with identifying specific physical self-perceptions, and developing scales to measure those self-perceptions. Phase one involved the initial classification of the specific physical self-perceptions after reviewing pertinent literature, and the re-examination of two inventories which had been recently employed in another study(Fox, Corbin, 1989). Finally, a pilot study was completed using an open-ended questionnaire that was designed by following the format Harter(1984) used in her development of the Perceived Competence Scale(Fox and Corbin, 1989). The open-ended questionnaire asked for a listing, in order of significance, those qualities which were considered important in the formation of a positive physical self(Fox and Corbin, $1989)$.

The questionnaire was given to 143 college students and then evaluated by an independent group of judges. Then, with 
the assistance of three content experts, the data were evaluated to determine the initial subgroupings for the inventory. Four categories were found, each endorsed by approximately 10 percent of the students. These included: perceived body attractiveness, sports competence, physical strength, and fitness and exercise(Fox and Corbin, 1989).

Phase two of the study was involved in developing the specific PSPP scale questions from the information gathered in Phase one(Fox and Corbin, 1989). Six questions were developed for each of the four subdomains. The questions were designed somewhat differently than previous inventories. The authors explain that "In order to provide a more complete and powerful subdomain coverage, product, process, and perceived confidence items were included"(Fox and Corbin, 1989, p. 413). For example for physical conditioning a product question was "Some people do not usually have a high level of stamina and fitness." A process question was "Some people feel that compared to most they always maintain a high level of physical conditioning." Finally, a perceived confidence question was "Others feel confident and at ease at all times in fitness and exercise settings." The questions were also written in the structured alternative format, which Harter(1982) had so much success with when she developed her Perceived Competence Scale. This format is designed to deter subjects from giving socially desirable responses to the questions.

In addition to the six questions for each of the four 
self-perception categories, six questions were developed to tap physical self-worth. These questions examined "feelings of pride, self-respect, satisfaction, and confidence in the physical self"(Fox and Corbin, 1989, p. 413). These five categories, when included with an inventory measuring general self-esteem, would allow for the testing of the hierarchical theory. The hierarchy has at the base the four physical selfperceptions or subdomains which are the most specific, next is the more general physical self-worth which is at a midrange level of generality, and finally is global self-esteem which is at the peak of the pyramid(Fox and Corbin, 1989).

The initial PSPP was given to six students for their criticism on the wording of the questions. After rewording a few of the questions, the inventory was given to 52 college students. Statistical means and standard deviations, along with histograms were determined for each item and scale. This statistical analysis showed that several of the items were skewed positively. This made it necessary to reword several of the questions "to make high scoring descriptors more extreme and low scoring descriptors less severe"(Fox and Corbin, 1989, p. 413).

The PSPP Validation

Phase three, which consisted of three different data collection sessions, was utilized to give the PSPP initial statistical review and to further correct any minor problems 
with the questionnaire. The data from phase 3 were also tested to determine whether the four self-perception scales were independent of each other and of the physical self-worth scale, thus displaying the multidimensional construct (Fox and Corbin, 1989).

The PSPP, the Rosenberg Global Self-Esteem Scale(SEI) (Rosenberg, 1965), and a physical activity questionnaire were given to 151 college students of a required English course. The means and standard deviations were determined for items, subscales and scales separating subjects by sex. Fox and Corbin(1989) also determined the scale and subscale reliability with Cronbach's coefficient alpha.

Finally, exploratory principal-component analyses were calculated for the four specific physical self-perceptions. Fox and Corbin(1989) did not include the physical self-worth scale in the analyses, reasoning that "this was hypothesized to be a superordinate construct in a hierarchical self-esteem structure"(p. 414). From the data received the four subscales developed a definite four-factor pattern. It was discovered, however, that the physical fitness category was not as clear as the other three categories. Due to this ambiguity the questions for this subdomain were adjusted to examine physical conditioning rather than fitness(Fox and Corbin, 1989).

The new conditioning subscale was evaluated by the assistants used in the Phase 1 analysis. Although the new category was found to be weaker than the original fitness 
category, it still met the requirements to be part of the inventory(Fox and Corbin, 1989). After this final adjustment in the questions, 234 students were given the modified questionnaire. The same statistics were developed as in the first data collection of Phase 3 , with the addition of a maximum-likelihood factor analysis, which allowed for the testing of significance of the contribution of each loaded factor to the covariance of the data(Fox and Corbin, 1989).

The final version of the PSPP and the SEI were given to 90 students in a general education class, as the third data collection for Phase 3. These data were used to test the "subscale stability through test-retest estimates, and also their susceptibility to socially desirable responses"(Fox and Corbin, 1989, p. 415). Half the group was given the questionnaire a second time 16 days later, while the other half repeated the questionnaire 23 days later. For the retest the Marlowe-Crowne Social Desirability Scale was included. Correlation coefficients were determined comparing the data from first and second tests. Correlations were also computed between item and subscale scores from the second test and the social desirability score.

The data from Phase four of the study were used to prove the structure of the PSPP, and to confirm the reliability and discriminant validity of the specific physical selfperceptions(Fox and Corbin, 1989). Fox and Corbin(1989) also used the data from Phase 4 to try and show that the four 
specific physical self-perceptions possessed criterion validity. This was achieved by examining relationships between the subdomains, global self-esteem and subjects' physical activity behavior(Fox and Corbin, 1989).

The questionnaire was administered to 355 college students in either a required English or communication studies class. The students were given the PSPP, the SEI, and a physical activity questionnaire. All descriptive statistics completed in Phase 3 were repeated with the Phase 4 data. Discriminant analysis was calculated investigating the relationship between the self-perception inventory and extent of participation in physical activity(Fox and Corbin, 1989). Canonical correlational analysis was also computed examining the relationship between type of activity and the PSPP.

Correlational analysis was employed to analyze how the five subscales relate among themselves, and how they relate with global self-esteem. Partial correlations, while withholding Physical Self-Worth, were also calculated to examine its function as an intermediary factor between global self-esteem and the four specific physical selfperceptions(Fox and Corbin, 1989). Finally, multiple regression analyses were calculated to investigate how strongly the Physical Self-Worth subscale represents the four specific physical self-perceptions(Fox and Corbin, 1989). 
Results of PSPP Analyses

There were many significant findings from the data collected in Phases three and four. For all subjects the subscale means were distributed around the mathematical average, which was 15(Fox and Corbin, 1989). The standard deviations were between 3.08 and 4.54 , for both groups. Fox and Corbin(1989) also found that the results remained quite stable. Reliability coefficients for the 16 day retest group were between .74 and .92 , while for the 23 day retest group the reliability coefficients were between .81 and .88 . The authors also found that Cronbach's coefficient alpha ranged between .81 and .92 for both males and females. All these results indicate that the specific self-perceptions are both internally reliable, stable, and that over a period of time test-retest responses remain constant(Fox and Corbin, 1989). The exploratory factor analyses found that with both sexes the four factors explained a large percentage of the variance between subscales. For the females, the four components explained $68.9 \%$ of the variance, while for males they explained $63.5 \%$ of the variance(Fox and Corbin, 1989). Likewise, with confirmatory factor analyses the four subdomains received statistical support. Fox and Corbin(1989) concluded from this that the four subscales represented independent components.

The questions in the PSPP were written in the structured alternative format. This question design was selected because 
of Harter's success in showing that it helped avoid socially desirable responses(Fox and Corbin, 1989). Analysis of the Marlowe-Crowne Social Desirability Scale scores found that only two PSPP items related to social desirability scores at a significant level(Fox and Corbin, 1989). These results indicate that the questions on the PSPP are not prone to socially desirable responses(Fox and Corbin, 1989).

An interesting aspect of the PSPP that Fox and Corbin(1989) investigated was how well the specific physical self-perceptions were able to predict a subject's involvement in physical activity. The authors first looked at the ability of the four subscales to distinguish between active and inactive subjects, using discriminant analyses. The tests yielded canonical correlation coefficients of .43 for males and .47 for females, which were highly significant(Fox and Corbin, 1989). The authors then completed a discriminant function equation and the subscales were able to correctly classify $70.4 \%$ of the males and $70.7 \%$ of the females as active or inactive(Fox and Corbin, 1989).

It was also determined that the condition subscale was the most dominant contributor for both males and females. Although it was the only significant factor for females, the strength and sport subscales were also found to be influential for the males(Fox and Corbin, 1989). The subscales were also able to accurately categorize active subjects into groups of either high levels or low levels of activity, with $69.9 \%$ of 
active females and $63.3 \%$ of active males being accurately categorized(Fox and Corbin, 1989). These results would indicate that the PSPP could be used as an evaluator not only between exercisers and non-exercisers, but also between individuals who are highly active and those who may not be as active.

One of the most important statistical evaluations was the testing of the hierarchical structure of the model. Fox and Corbin(1989) developed their model on the premise that the Physical Self-Worth subscale was above the specific physical self-perceptions, but below global self-esteem. They further explained that "A test of the construct validity of the PSW lies in its relationships with the other PSPP subscales and global self-esteem in the hypothesized hierarchical self-esteem structure"(Fox and Corbin, 1989, p. 423).

For this to be demonstrated the physical self-worth component would have to be more highly related to global selfesteem than any of the other four sub-domains(Fox and Corbin, 1989). Zero-order correlations found that indeed the correlation between global self-esteem and PSW was .64 for females and .61 for males. Meanwhile, the correlations between the four specific self-perception subscales and global self-esteem ranged between .17 and .48(Fox and Corbin, 1989). It was also determined that the four subscales correlated higher with PSW than with global self-esteem, with these 
correlations ranging from .32 up to .74 . These results enhance the theory that self-concept is hierarchically structured.

An important aspect of physical self-worth is its role as a mediating variable between the specific self-perceptions and global self-esteem(Fox and Corbin, 1989). To determine how influential physical self-worth was, partial correlations while controlling for PSW were completed. Fox and Corbin(1989) found that all but one of the relationships between global self-esteem and the specific subscales fell below significant levels when PSW was removed. The exception was the physical condition scale which remained significant at the .05 level with a correlation coefficient of .20 , all other scale coefficients ranged between -.03 and .06 (Fox and Corbin, 1989). These results offer further support to the hierarchical structure of self-esteem, and to the role that physical self-worth plays as an intermediary between the specific self-perceptions and general self-esteem.

One last analysis was the stepwise multiple regression. Fox and Corbin(1989) attempted to see how well the four subscales could predict physical self-worth. It was found that the four subscales explained $68 \%$ of the variance for males and $69 \%$ of the variance for the females. This further supports the theory that the PSW is a superordinate variable. Fox and Corbin(1989) believe that these results support their choice of the four specific physical self-perceptions as the 
factors with which to evaluate the development of a physical self-worth for their subject population.

In summary, Fox and Corbin(1989) have been able to show that the hierarchical model may exist in the physical realm, and that the PSPP is a new inventory which may be used to test this concept. However, before any conclusions can be made more research testing the hierarchical model using the PSPP is necessary. It is important to remember that past research had often used poorly validated inventories, which led to studies being completed only once(Sonstroem, 1984). Because the PSPP has been found to be valid with college students, further research with the inventory is important, and necessary . 
Methodology

This chapter is divided into three sections. These sections are: (a) Subjects, (b) Instruments, and (c) Statistical Analyses. Some sections have several subsections.

\section{Subjects}

Subjects for this study were 261 adult volunteers between the ages of thirty and sixty-five from several intact groups, who signed informed consent forms (Appendix B) to participate in the study. The subjects were selected from the saint Nicholas Greek orthodox Church community in Lexington, Massachusetts $(n=161)$; members of the YMCA in Melrose, Massachusetts $(n=64)$; employees of Coldwell Bankers Realtors Corporation in North Kingstown, Rhode Island $(n=10)$; participants in the Adult Fitness program at the University of Rhode Island( $n=11)$; and members of the Senior Swim program at the University of Rhode Island $(n=15)$.

Each subject received a questionnaire package(Appendix C). The package included; written directions, the Physical Self-Perception Profile(PSPP)(Fox and Corbin, 1989), the Rosenberg Self-Esteem Inventory(SEI) (Rosenberg, 1965), five questions on the exercise history of the individual(Fernhall and Ausmus, 1987), and a computer answer sheet. Verbal 
directions were also given to individuals as they received the questionnaires. It was explained that there were no right or wrong answers, and that they should answer each question as to how it relates to them personally. It was also explained that the answers were strictly confidential with no names being attached to the questionnaires. The subjects were asked to complete the questionnaire immediately if possible. However, they were allowed to take the questionnaire home if they preferred.

\section{General Population}

The subjects were divided into two groups, a general population group and an organized fitness group. The general population group included the church members, YMCA members, and Coldwell Banker employees. Subjects were predominantly caucasian, educated, and economically well established.

The church was visited several times over a three month period, where subjects were recruited. The subjects were asked to complete the questionnaire immediately, however, if they were pressed for time subjects were given the option to take the questionnaire home. Questionnaires were collected on subsequent visits to the church, with most subjects returning the survey within two weeks of reception. Similarly, the YMCA was visited frequently over a two week period. Several different activity classes were attended, where subjects were recruited. Again the subjects were 
invited to complete the questionnaires immediately. Several subjects chose instead to take the packet home with them, which required revisiting the class to collect the completed questionnaires. The Coldwell Banker office was visited and questionnaires were distributed to those employees who were interested. Several return trips to the office were necessary in collecting the completed packets.

\section{Organized Fitness Population}

The second group consisted of individuals who participated in known established fitness programs. These programs included the Adult Fitness Program, the Adult Swim Class both at the University of Rhode Island, and YMCA members enrolled in conditioning classes. The Adult Fitness Program is conducted at the University of Rhode Island. The program was visited on several different mornings to recruit subjects and collect completed questionnaires. For the Senior Swim Class, the professor was given several packages and asked to distribute them to her students. Over a two week period the students were asked to take a questionnaire at the end of class and return it at the next class meeting. The YMCA members were individuals who participated in aerobics classes. Over a two week period several different classes were attended and questionnaires distributed. Then follow-up visits were required to collect the completed questionnaires. 


\section{Instruments}

\section{PSPP Inventory}

The first thirty questions of the questionnaire were the PSPP(FOx and Corbin, 1989). No changes were made to the inventory format from the original study. This inventory was designed to measure specific physical self-perceptions, and the more general physical self-worth. The specific physical self-perception scales include: sports competence, attractive body, physical strength, and physical condition(Fox and Corbin, 1989).

The questionnaire was designed to examine the construct of self-esteem within the physical domain. The questions were designed to protect from socially desirable responses. Fox and Corbin(1989) used a four-choice structured alternative format. Harter(1982) found that the structured alternative format was helpful in avoiding socially desirable responses. Fox and Corbin(1989) have shown initial validity and reliability of the PSPP as an inventory in measuring specific physical self-perceptions.

The PSPP consists of thirty questions. Six questions for each of the five factors. Questions 1, 6, 11, 16, 21, and 26 were for sports competence, and examined overall perceptions of sport and athletic ability. The physical condition factor examined perceptions of level of conditioning, fitness and ability to exercise, and was covered by questions $2,7,12,17,22$, and 27 . The next factor was 
attractive body, which was covered by questions $3,8,13,18$, 23 , and 28 , and measured perceptions of having an attractive body. The fourth specific self-perception was physical strength and musculature, which looked at perceptions of strength and muscular condition, and was covered by questions $4,9,14,19,24$, and 29. Finally, there was the physical self-worth component, which measured general feelings about the physical self, and included questions $5,10,15,20,25$, and 30 .

\section{Rosenberg SEI}

The next ten questions on the inventory were the Rosenberg SEI items(Rosenberg, 1965). These questions are aimed to tap the overall self-esteem perceptions of an individual. This is a unidimensional inventory that focuses strictly on global self-esteem. In conjunction with the PSPP it is used to determine whether there is a hierarchical structure to self-concept. Fox and Corbin(1989) used the Rosenberg SEI, and were successful in demonstrating that a hierarchy exists. In this study the SEI is a four point scale, going from strongly agree to strongly disagree. The Rosenberg(1965) SEI has received statistical support, and is one of the more accepted global self-esteem inventories(Harter, 1983). 


\section{Exercise History}

The last five questions were developed from a similar questionnaire on exercise history by Fernhall and Ausmus(1987). The questions were designed to examine the exercise habits of the subjects(Appendix C). The questions were designed to determine not only whether a subject exercises, but how long the subject had been exercising, how often they exercise, the duration of an average exercise session, and exactly what types of activities the subjects participate in regularly.

The questions were the same as in the Fernhall and Ausmus(1987) study with a few revisions. The original study used open ended questions. In this study the subjects were given four choices for each question, except for the first which was a simple yes or no. The question about how many days per week do you exercise, the four alternatives were: one day per week; two days per week; three days per week; and more than three days per week. The duration question was broken down into: less than twenty minutes; twenty to thirty minutes; thirty to sixty minutes; and more than one hour.

The multiple-choice format was preferred over the open ended format for several reasons. First, this style of question provides greater objectivity in scoring. With four possible answers, the selection could be entered directly onto the computer answer sheet. The specificity of exercise habit would allow for the evaluation of subjects with a variety of 
exercise habits, instead of just comparing those who exercise and those who do not exercise. This information would help in the evaluation of the PSPP between active and non-active adults.

\section{Statistical Analyses}

All the data were entered onto computer answer sheets, and given an identification number. The completed answer sheets were then read at the academic computer center. All PSPP and SEI scale scores were coded so that higher scale scores indicated more favorable self-perceptions.

Voluntary exercise participation was analyzed in the following manner. Subjects were categorized first as either exercisers or non-exercisers based on their response("yes" or "no") to question 4l. For people who exercised, extent of participation was assessed by multiplying response scores from questions 43 and 44 . This provided an extent of participation value, which was a combination of the number of days per week a subject exercised, and the number of hours per week they exercised. Finally, comparisons were made on PSPP scale scores between subjects in organized exercise programs ( $n=50)$, and subjects in the general population( $n=210)$.

Data were analyzed at the University of Rhode Island Academic Computer Center. The analyses were divided into two main categories: scale structures and relationships, and criterion validity. Means, standard deviations, and internal 
consistencies were first calculated for all PSPP scale scores. Visual comparisons were made with descriptive data from the Fox and Corbin(1989) student sample. This information would be used to determine whether the older adult subjects had similar results to the college students. Relationships among PSPP scales, and with self-esteem were then examined to assess the hierarchical validity of the Fox model in this older population. Principal component analysis using parallel analysis(Allen and Hubbard, 1986), and the minimum average partial(MAP) analysis(Velicer, 1976) were conducted to examine the internal structure of the PSPP scales.

All statistics used were similar those used in the study by Fox and Corbin(1989). A significance level of .05 was used as the break point for all statistics. Other than in the principal component analysis, the Statistical Package for the Social Sciences(SPSS-X)(1988) was employed. Statistical analyses included the calculation of means, standard deviations, Cronbach alpha's, Pearson 's, partial correlation coefficients, and discriminant functions. Finally, two-way analysis of covariance was calculated, which employed sex and exercise group membership as factors, and age as a covariate. Finally, as was explained at the beginning of this section, criterion validity was evaluated using self-reports of exercise participation as the criterion variable. 


\section{Results and Discussion}

This chapter consists of several different sections. The first main section is titled scale structures and Relationships and treats the internal structure of scales and relationships between scales. This part has several subsections: a)scale descriptive statistics, b) scale internal consistencies, c) relationships between scales,

d) exploratory factor analysis, and summary. Tests of hypotheses 1 and 2 will be covered in section (c) above. The second section is titled Criterion Validity. This section compares PSPP scale scores of a)exercisers versus nonexercisers, b) groups formed on the basis of extent of participation, and c) scores of people belonging to formal exercise groups versus those who do not, and d)summary of criterion validity. The third section is Discussion. The fourth section is Practical Applications. The final section is Implications for Future Research.

\section{Scale Structures and Relationships}

Scale descriptive statistics

There were 260 people who participated in the study. The general population group consisted of 210 subjects. The organized fitness population had fifty subjects. In total, there were 149 female, and 111 male subjects. The average 
age was 44.08 years with a standard deviation of 11.58 . The subjects ranged in age between thirty and sixty-five.

For both female and male subjects the mean, standard deviation, range, kurtosis, and skewness for all five PSPP scales can be found in Table 1.

TABLE 1

Scale Descriptive Statistics

M SD Range Kurt. Skew.

Females

$\begin{array}{lllllr}\text { PSW } & 15.73 & 4.31 & 18.00 & -0.24 & -0.33 \\ \text { Sport } & 13.43 & 4.67 & 18.00 & -0.59 & 0.31 \\ \text { Condition } & 15.95 & 4.84 & 18.00 & -0.64 & -0.30 \\ \text { Body } & 14.82 & 4.50 & 18.00 & -0.69 & -0.24 \\ \text { Strength } & 15.16 & 4.11 & 18.00 & -0.26 & -0.18\end{array}$

Males

\begin{tabular}{lccccc} 
PSW & $16.89 *$ & 3.66 & 17.00 & 0.36 & -0.33 \\
Sport & $15.60 *$ & 4.28 & 18.00 & -0.53 & 0.21 \\
Condition & 16.36 & 4.06 & 17.00 & -0.66 & 0.11 \\
Body & $15.86 *$ & 3.86 & 18.00 & -0.09 & -0.08 \\
Strength & $16.15 *$ & 3.77 & 17.00 & -0.18 & -0.08 \\
\hline
\end{tabular}

*males greater than females, $\mathrm{p}<.03$ to $\mathrm{p}<.001$. 
The female subjects in this study had somewhat higher average scores for all scales than the females in the study completed by Fox and Corbin(1989), with the exception of the sports competence scale. Both middle-aged females and college females had the highest average score in the physical condition category. However, the middle-aged females had an average of 15.95 with a standard deviation of 4.84 , while the college-aged females had an average of 14.93 with a standard deviation of 4.05 . The only scale that the college-aged females had a higher average was the sports competence scale. The college females had an average of 14.49 with a standard deviation of 4.23, while the middle-aged females had an average of 13.43 with a standard deviation of 4.67 .

The male subjects had significantly higher average scores $(\mathrm{p}<.03$ to $\mathrm{p}<.001)$ for all PSPP scales than the females, except for the condition scale. In comparison to the male subjects in the Fox and Corbin(1989) study the only scale that was distinctly higher for the middle-aged males was the attractive body scale. The males in this study had an average score of 15.86 with a standard deviation of 3.86 , while the college-aged males had an average score of 14.91 with a standard deviation of 3.54. The strength and musculature scale average was also higher for the middle-aged males. However, similar to the females, the sports competence scale average was higher for the college-aged males. The Fox and Corbin(1989) subjects had a scale mean of 17.24 with a 
standard deviation of 3.85, while these subjects had a scale mean of 15.60 with a standard deviation of 4.28 .

The responses for each scale covered the full range of possible scores. There were six questions with four possible answers for each category, thus the range was from six to twenty-four, or eighteen. For the female subjects the scores were spread over the full range, while the male subjects had ranges of either seventeen or eighteen for all scales.

The skewness results show that the scores are quite close to a symmetrical pattern. For the females the scales were all skewed slightly negative, except for the sports competence category which was skewed slightly positive. For the male subjects, the scales were also quite close to a symmetrical distribution. There were three that were skewed slightly negative, physical self-worth, body, and strength. The categories of sport, and condition were both skewed slightly positive.

The kurtosis results show that the scale responses were quite close to a normal distribution. For both the females and male subjects response distribution was slightly flatter than a normal distribution. The only category that was more peaked was the physical self-worth responses for the male subjects. However, for both skewness and kurtosis, because the values are quite close to zero it indicates that the responses were spread symmetrically, and quite close to a normal distribution(Ferguson, 1966). 
Scale Internal Consistencies

Internal consistency analyses were performed for all scales(Table 2).

TABLE 2

Scale Internal Consistencies: Cronbach Alphas

Females Males

$\begin{array}{lll}\text { Sport } & 0.904 & 0.898 \\ \text { Condition } & 0.913 & 0.859 \\ \text { Body } & 0.896 & 0.873 \\ \text { Strength } & 0.899 & 0.898 \\ \text { PSW } & 0.898 & 0.876 \\ \text { SEI } & 0.870 & 0.860\end{array}$

A strong alpha score indicates that "The parts all measure the same trait, or traits, to about the same degree" (Guilford and Fruchter, 1973, p. 419). The present results offer strong support that each of the different scales contain items measuring the same thing. For the males, the alphas ranged between 0.859 and 0.898 , with physical condition being the lowest. Similarly, the alphas for the females ranged between 0.870 and 0.913 , with attractive body being the lowest. The alphas for the PSPP scales were all similar to the alpha of the better-known SEI. This indicates that the internal 
consistency values for the Fox scales were at least as good as the internal consistency values for the standardized Rosenberg self-esteem scale in this middle-aged population.

\section{Relationship Between Scales}

Zero-order correlation coefficients between selfperception variables for both females and males can be found in Table 3. For both females and males the correlation coefficients were all highly significant $(p<.001)$.

Test of hypothesis 1: Physical self-worth will be significantly related to global self-esteem. Hypothesis 1 was tested by Pearson $r$ coefficients calculated between PSW and SEI scores. Table 3 shows a coefficient of $0.584(p<.001)$ for females and a coefficient of $0.566(p<.001)$ for males. Based upon these values the null hypothesis was rejected. It was concluded that physical self-worth is significantly related to global self-esteem.

Test of hypothesis 2: The physical self-perception components of sports competence, physical conditioning, attractive body, and physical strength will be more highly related to physical self-worth than to global self-esteem. Examination of Table 3 reveals coefficients of .548, .690, .785, and .555 between PSW and sport, condition, body, and strength scales respectively for the female subjects. 
TABLE 3

Zero-order Correlation Coefficients Among

$\underline{\text { Self-Perception Variables }}^{\mathrm{a}}$

Esteem PSW Sport Cond. Body

\begin{tabular}{|c|c|c|c|c|c|}
\hline Females & & & & & \\
\hline PSW & .584 & & & & \\
\hline Sport & .291 & .548 & & & \\
\hline Condition & .305 & .690 & .531 & & \\
\hline Body & .564 & .785 & .328 & .546 & \\
\hline strength & .247 & .555 & .555 & .608 & .289 \\
\hline Males & & & & & \\
\hline PSW & .566 & & & & \\
\hline Sport & .476 & .623 & & & \\
\hline Condition & .319 & .696 & .519 & & \\
\hline Body & .544 & .798 & .541 & .609 & \\
\hline strength & .379 & .642 & .574 & .504 & .516 \\
\hline
\end{tabular}

all values significant at $\mathrm{p}<.001$

Comparatively, female coefficients between SEI and sport, condition, body, and strength were somewhat lower, .291, .305, .564, and .247 respectively. The significance of these differences was tested by the use of a t-ratio (Ferguson, 
1966, p.189) which is printed below.

$$
t=\frac{\left(r_{12}-r_{13}\right) \sqrt{(N-3)\left(1+r_{23}\right)}}{\sqrt{2\left(1-r_{12}{ }^{2}-r_{13}{ }^{2}-r_{23}{ }^{2}+2 r_{12} r_{13} r_{23}\right)}}
$$

where, in the present research $\mathrm{r}_{12}=$ the coefficient between a subscale(e.g. sport) and PSW; $r_{13}=$ the coefficient between SEI and the subscale; and $\mathrm{r}_{23}=$ the coefficient between SEI and PSW.

Table 4 presents the t-ratios developed in these analyses for each of the subscales. All coefficient comparisons were significant $(p<.05$ to $p<.01)$ with coefficients developed between subscales and PSW larger in every case than coefficients developed between subscales and SEI. Based upon these analyses the null hypothesis of no difference between coefficients was rejected. It was concluded that subscales are more highly related to physical self-worth than they are to global self-esteem. These analyses support the hierarchical structure of the PSPP scales. The hierarchical structure of the Fox model is also supported by the larger, though not significant, size in Table 3 of coefficients developed between PSW and SEI as compared to coefficients developed between sport, condition, body, strength and SEI.

To further test the hierarchical structure of the PSPP scales, and the importance of the physical self-worth domain 
TABLE 4

Comparison of Subscale Coefficients With Physical

Self-Worth and Global Self-Esteem

Subscale

PSW

SEI

t

Female Analyses

$\begin{array}{lrrr}\text { Sport } & .548 & .291 & 12.25 \\ \text { Condition } & .690 & .305 & 7.15 \\ \text { Body } & .785 & .564 & 4.84 \\ \text { Strength } & .555 & .247 & 5.20\end{array}$

Male Analyses

$\begin{array}{lccc}\text { Sport } & .623 & .476 & 2.14 \\ \text { Condition } & .696 & .319 & 5.90 \\ \text { Body } & .798 & .544 & 4.60 \\ \text { Strength } & .642 & .379 & 3.83\end{array}$

$$
\begin{aligned}
& t_{.05}=1.66 \\
& t_{.01}=2.36
\end{aligned}
$$

as an intermediary variable, partial correlations were computed between subscales and global self-esteem controlling for physical self-worth(Table 5). When physical self-worth was controlled, the relationships between the specific selfperceptions and global self-esteem all decreased dramatically. For the female subjects, there was one self-perception 
TABLE 5

Comparison of Zero-Order and Partial Correlation

Coefficients Controlling for Physical Self-Worth

Esteem

Females

Males

Zero Partial Zero Partial

\begin{tabular}{lcccc} 
Sport & .292 & -.046 & .476 & .19 * $^{\text {Condition }}$ \\
Condy & .305 & -.140 & .319 & -.127 \\
Body & .565 & $.232 \star$ & .545 & .187 * \\
Strength & .248 & -.099 & .379 & .025 \\
\hline
\end{tabular}

$\star \mathrm{p}<.01$

subscale, attractive body, that maintained a significant (p<.0I) relationship with global self-esteem. The coefficient dropped from 0.564 to 0.231 , when the effects of physical self-worth were removed. This differs from the college-aged females in the Fox and Corbin study(1989). For the females in that study the only subscale to retain a significant relationship with global self-esteem, while controlling physical self-worth, was physical condition. The coefficient in that situation dropped from .30 to .20.

The male subjects had two subscales, sports competence, 
and attractive body, that preserved their significant $(p<.01)$ relationship with global self-esteem when physical self-worth was controlled. The coefficient for attractive body with males dropped from 0.544 to 0.186 , and for sports competence from 0.476 to 0.190 . These results also differ from the Fox and Corbin(1989) findings with their male subjects. When physical self-worth was controlled, none of the subscales maintained a significant relationship with global selfesteem.

A further examination of Table 3 reveals Pearson r's between PSW and body scales of .785 and .798 for females and males, respectively. Coefficients this large tend to indicate the non-independence of constructs(i.e., more than $50 \%$ of the variance in variables is shared variance). This condition would tend to minimize the utility of PSW when used in conjunction with the body scale. This same condition appears to have existed in the Fox and Corbin(1989) data in that they obtained coefficients of .71 in females and .74 in males, however, the authors failed to comment on these results.

\section{Exploratory Factor Analysis}

Principal component analyses of female and male item responses were performed to test the internal structure of the scales. Most importantly, they were completed to determine whether the test items formed the same component structure in an older adult population as compared to a 
college-aged population. Additionally, since fox had not submitted his PSW items to a principal component analysis together with the subscale items, PSW items were included in the present analysis. If the PSW scale is to be used in conjunction with the four subscales, then its items should be independent of the items from the other scales.

In obtaining the correct principal component solution, the appropriate number of components to be rotated is crucial. Zwick and Velicer(1985) have identified the parallel analysis of Horn(1965) and the minimum average partial(MAP) analysis of Velicer(1976) as two of the best procedures for identifying the proper number of components to rotate. The present study applied the parallel analysis(Allen and Hubbard, 1986), and the minimum average partial(MAP) analysis(Velicer, 1976) in determining the proper number of components to rotate. All thirty items(six for each of the five scales) were submitted to the principal component analysis with varimax rotation. An a priori decision was made to include only items with factor loadings equal to or greater than 0.40 .

Females. The results from the exploratory factor analysis following varimax rotation for females are in Table 6. Both the parallel analysis and the MAP method derived four components. These four factors in total explain $68.17 \%$ of the variance among subscale items. The sport competence items were the only items to match-up completely with one of the components, with no other items from other scales overlapping 
Table 6

Exploratory Factor Analysis - Females

Principal Component Analysis - Varimax Rotation

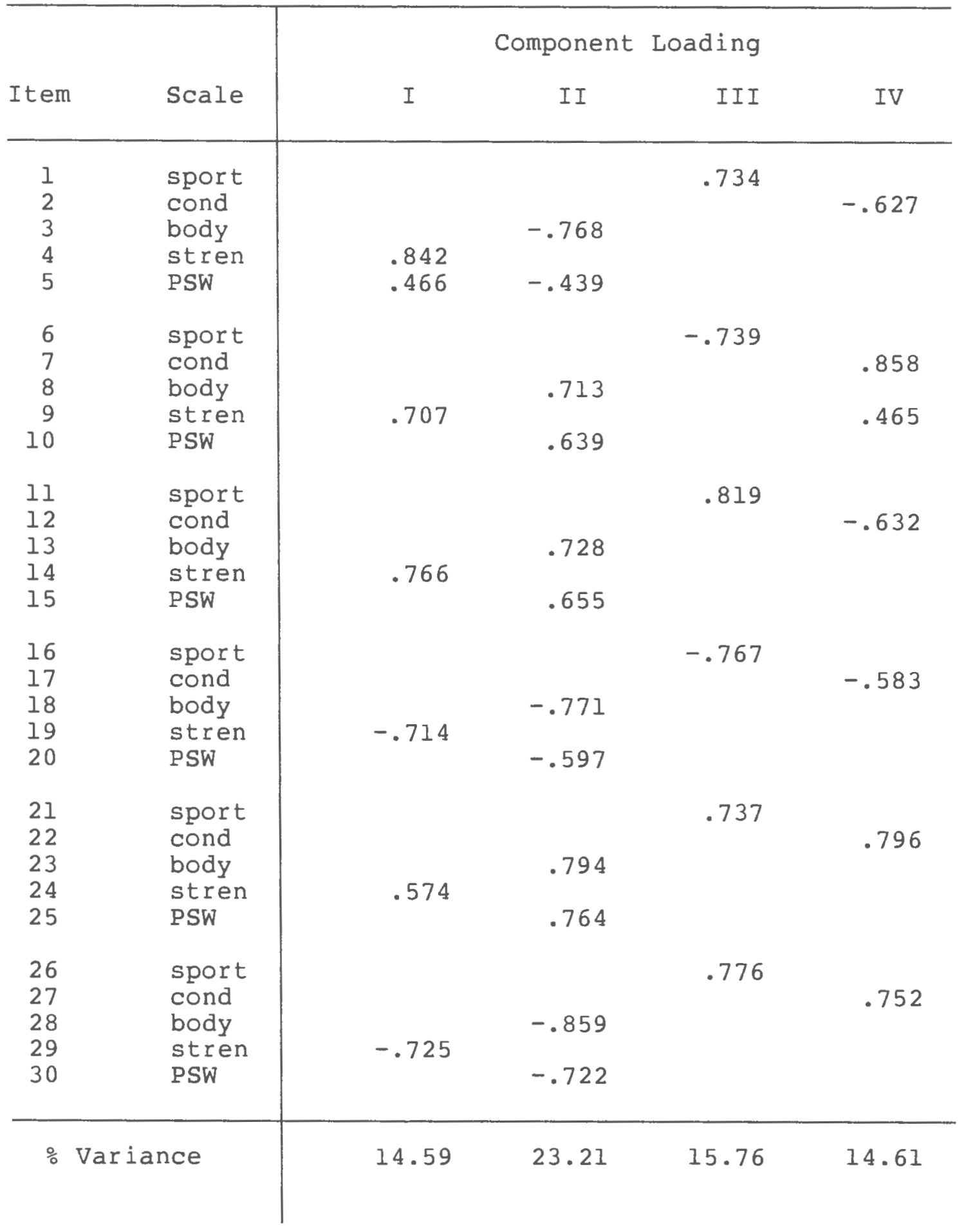


onto that component.

The physical condition, and strength factors also matched-up, however in both cases there was some item overlap. For physical condition, not only did all six condition items load on one factor, but a strength item also loaded. For the strength items, again all six loaded onto one component, but one PSW item also load on that component. This indicates that there was a slight amount of item overlap among scales.

The body items and PSW items showed the most confounding results. Every item within the body scale, and every item within the physical self-worth scale factored out onto the second component. This signifies that there is a great deal of overlap between the two scales.

A second principal component analysis with varimax rotation was completed, where a five component solution was requested. This was performed since it had been expected that five components would fall-out initially. It was found that the fifth component did not produce any items that loaded above the .40 cut-off point.

Males. The results of the principal component analysis for the males are in Table 7. The parallel analysis selected four components to rotate, while the MAP method identified five components. The fifth factor, however, had no true structure. There were only three items with component loadings above the .40 limit, and all three were very close to the this limit. All three items also loaded on one of the 
other factors, and loaded higher on those other factors than on the fifth one. Because the four factors from the fourcomponent solution matched closely with the first four factors from the five-component solution, it was decided to present the four factors from the parallel analysis. These four factors in total explained $64.71 \%$ of the variance among subscale items.

The male results produced greater scale overlap than the female results. The fourth component contained five of the six condition items, with the sixth item loading on the strength category. The sport competence items were the next most successful. All six sport items loaded on the third component, with only one external item being selected, that from the body category.

The strength and body factors were the most puzzling. The first component loaded attractive body items and physical self-worth items. There was also one physical condition item that loaded onto the first component. Similarly, the second component, identified not only strength items but also physical self-worth items and several condition items.

Summary. Based on the previous analyses, this thesis section, Scale Structure and Relationships, makes the following conclusions. The subscales of sports competence, physical condition, attractive body, and strength and musculature appear to be identifiable as separate constructs. While they are related to each other, the principal component 
Table 7

Exploratory Factor Analysis - Males Principal Component Analysis - Varimax Rotation

\begin{tabular}{|c|c|c|c|c|c|}
\hline \multirow[b]{2}{*}{ Item } & \multirow[b]{2}{*}{ Scale } & \multicolumn{4}{|c|}{ Component Loading } \\
\hline & & I & II & I I I & IV \\
\hline 1 & sport & & & -.692 & \\
\hline 2 & cond & & & & -.529 \\
\hline 3 & body & -.647 & & & \\
\hline 4 & stren & & .809 & & \\
\hline 5 & PSW & & .555 & & \\
\hline 6 & sport & & & .672 & \\
\hline 7 & cond & & & & .876 \\
\hline 8 & body & .787 & & & \\
\hline 9 & stren & & .764 & & \\
\hline 10 & PSW & .541 & & & \\
\hline 11 & sport & & & -.759 & \\
\hline 12 & cond & & -.407 & & -.572 \\
\hline 13 & body & .721 & & & \\
\hline 14 & stren & & .774 & & \\
\hline 15 & PSW & .535 & -.460 & & \\
\hline 16 & sport & & & .823 & \\
\hline 17 & cond & & -.440 & & \\
\hline 18 & body & -.429 & & .433 & \\
\hline 19 & stren & & -.800 & & \\
\hline 20 & PSW & -.480 & .407 & & \\
\hline 21 & sport & & & -.710 & \\
\hline 22 & cond & & & & .822 \\
\hline 23 & body & .759 & & & \\
\hline 24 & stren & & .637 & & \\
\hline 25 & PSW & .700 & & & \\
\hline 26 & sport & & & .771 & \\
\hline 27 & cond & -.434 & & & .692 \\
\hline 28 & body & -.797 & & & \\
\hline 29 & stren & & -.671 & & \\
\hline 30 & PSW & -.767 & & & \\
\hline$\% \mathrm{~V}$ & nce & 20.84 & 17.84 & 15.16 & 10.87 \\
\hline
\end{tabular}


analyses indicate only a minimum amount of scale overlap between them. The same statement may not be made for the PSW scale, however. Items from this scale repeatedly loaded on the attractive body component. Most importantly, no factor, identifiable as Physical Self-Worth was revealed in any of the principal component analyses.

The lack of independence between the PSW and the body scales can be observed also by closer examination of Table 3 . While Cronbach states that "It is very unusual for a validity coefficient to rise above .60"(Cronbach, 1960, p. 115), he also discusses the existence of validity coefficients which may be too large, thus invalidating the independence of constructs(p.248). Independence can be assessed by subtracting the squared validity coefficient from the reliability coefficient. Doing this for females entails squaring the value of .785 and subtracting from .898. This leaves only $28 \%$ of unique variance for the PSW scale as compared to $62 \%$ common variance shared with the body scale. For males, unique PSW variance was even lower at $24 \%$. Clearly, these results indicate a major limitation in the PSW scale.

\section{Criterion Validity}

Hypothesis 3: The Physical Self-Perception Profile scales will significantly predict levels of physical activity as reported by subjects. This hypothesis was tested 
in three ways: first, by subject self-description as exerciser or non-exerciser; second, by extent of participation; and third, by those subjects in an organized fitness program, and the subjects in the general population.

\section{Exercisers Versus Non-Exercisers}

The subjects were classified by how they responded to question 41 (Appendix $C$ ), which was a simple yes or no question.

Females. There were 102 female subjects who responded "yes" to question 41, thus classifying themselves as exercisers. Forty-seven of the 149 subjects classified themselves as non-exercisers.

Scale means and standard deviations were calculated for female exercisers and non-exercisers(Table 8 ). The means of the PSPP factors for exercisers ranged from 14.55 to 18.20 , with the standard deviations ranging between 3.53 and 4.63 . The non-exercisers had factor means between 10.96 and 13.15, with the standard deviations ranging between 3.20 and 4.34 . The component with the lowest mean for exercisers was sports competence, while for non-exercisers it was physical condition. The highest factor for exercisers was physical condition, while for the non-exercisers it was strength. It is apparent from Table 8 that exercisers scored higher on all PSPP scales and also on the SEI scale than did non-exercisers, however these were not tested for significance. 
Means and Standard Deviations: Exercisers vs. Non-Exercisers

\begin{tabular}{|c|c|c|c|c|}
\hline & \multicolumn{2}{|c|}{$\begin{array}{l}\text { Exercisers } \\
(n=102)\end{array}$} & \multicolumn{2}{|c|}{$\begin{array}{l}\text { Non-Exercisers } \\
(n=47)\end{array}$} \\
\hline & Mean & S.D. & Mean & S.D. \\
\hline Sport & 14.55 & 4.63 & 11.06 & 3.85 \\
\hline Condition & 18.20 & 3.53 & 10.96 & 3.20 \\
\hline Body & 15.95 & 4.10 & 12.30 & 4.34 \\
\hline Strength & 16.05 & 3.78 & 13.15 & 3.73 \\
\hline PSW & 17.09 & 3.73 & 12.81 & 4.03 \\
\hline SEI & 34.26 & 4.47 & 31.85 & 5.75 \\
\hline
\end{tabular}

A stepwise discriminant analysis was then completed to see which scales had a predictive function in the classification of the female subjects. The analysis developed a significant discriminant function( $\mathrm{r}=.713, \mathrm{p}<.001)$ which selected condition, first, and strength, second, as significant predictors. The standardized betas were 1.13 for the condition variable, and -0.28 for the strength variable. Sports competence, attractive body, physical self-worth, and global self-esteem were not selected as significant predictors.

Table 9 presents the classification table for the 
analysis. The discriminant function analysis was able to properly classify $84.56 \%$ of all female subjects. The analysis was able to correctly predict $83.2 \%$ of the exercisers, and $89.4 \%$ of the non-exercisers. These "hit" values are then compared to the base rate to examine whether the function analysis classified the subjects better than chance. The base rate is obtained by dividing the number of subjects in a group by the total number of subjects. Therefore the base rate for female exercisers was

Table 9

Subject Classification: Exercisers versus Non-Exercisers

FEMALES

Predicted Group

Actual Group $\quad$ No. of Cases $\quad 1 \quad 2$

$\begin{array}{llll}\text { Exercisers } & 102 & 84 & 18\end{array}$

$(68.5 \%) \quad(82.4 \%) \quad(16.6 \%)$

Non-Exercisers

47

5

42

$(31.5 \%)$

$(10.6 \%)$

$(89.4 \%)$

Percent Correctly Classified - $84.56 \%$

68.5\%(102/149), and for non-exercising females it was 
$31.5 \%(47 / 149)$. From this information it was concluded that the equation was able to predict both groups of females with relatively equal accuracy, and with a success rate better than chance.

Males. Scale means and standard deviations were calculated for male exercisers and non-exercisers(Table 10). Of the 111 male subjects 69 answered "yes" to question 41 (Appendix C), categorizing themselves as exercisers, while 42 were classified as non-exercisers. The means for the Table 10

Means and Standard Deviations: Exercisers vs. Non-Exercisers MALES

$\begin{array}{cc}\text { Exercisers } & \text { Non-Exercisers } \\ (n=69) & (n=42) \\ \text { Mean S.D. } & \text { Mean }\end{array}$

\begin{tabular}{lllll} 
Sport & 16.36 & 4.18 & 14.36 & 4.20 \\
Condition & 18.23 & 3.47 & 13.29 & 2.93 \\
Body & 16.55 & 3.75 & 14.73 & 3.80 \\
Strength & 16.54 & 3.62 & 15.52 & 3.97 \\
PSW & 17.62 & 3.53 & 15.69 & 3.59 \\
SEI & 34.14 & 4.63 & 33.71 & 4.54 \\
\hline
\end{tabular}

male exercisers, on the five PSPP categories, ranged between 
16.36 and 18.23, with standard deviations between 3.47

and 4.18. The non-exercisers had factor means between 13.29 and 15.69, with standard deviations ranging between 2.93 and 4.20. The self-perception with the lowest mean for exercisers was sports competence, and the highest mean was physical condition. The non-exercisers had physical condition with the lowest mean, while physical self-worth had the highest. Exercisers also had a higher mean on the Rosenberg SEI than the non-exercisers. Exercisers had a mean of 34.14 with a standard deviation of 4.63 , while nonexercisers had a mean of 33.71 with a standard deviation of 4.54. Although the exercisers had higher means than the nonexercisers the significance of difference was not calculated.

A stepwise discriminant analysis was then completed to determine the ability of study scales in classifying male exercisers and non-exercisers. The analysis developed a significant discriminant function( $r=.641, p<.001)$ which selected three factors, physical condition, strength, and physical self-worth, in that order. The standardized betas for the three were $1.34,-0.28$, and -0.44 , respectively. Sports competence, attractive body, strength, and global selfesteem were not significant predictors.

Using the three variables selected, subjects were classified as exercisers and non-exercisers(Table 11). The discriminant function equation was able to correctly categorize $78.38 \%$ of all the male subjects. The equation 
correctly placed $78.3 \%$ of the exercisers, and $78.6 \%$ of the non-exercisers. These "hit" values are greater than the base values of $62.2 \%(69 / 111)$ for exercisers and $37.8 \%(42 / 111)$ for non-exercisers. The equation was able to predict male participation and non-participation with equal accuracy, and with a success rate better than chance.

Table 11

Subject Classification: Exercisers versus Non-Exercisers

MALES

Predicted Group

Actual Group No. of Cases $\quad 1 \quad 2$

$\begin{array}{lccc}\text { Exercisers } & 69 & 54 & 15 \\ & (62.2 \%) & (78.3 \%) & (21.7 \%) \\ \text { Non-Exercisers } & 42 & 9 & 33 \\ & (37.8 \%) & (21.4 \%) & (78.6 \%)\end{array}$

Percent Correctly Classified $-78.38 \%$ 


\section{Extent of Participation}

A second series of discriminant analyses were completed with exercisers being separated into smaller groups by extent of participation. As discussed in Chapter 3 the responses to the questions were scored from one to four. For question 43, how many days per week do you exercise? (Appendix C), a score of one was for answering one day per week, two was given to two days per week, three for three days per week, and a score of four was given if the subject answered more than three days per week. For question 44, how many minutes per day do you exercise?(Appendix C), a score of one was for less than 20 minutes per day, two for 20 to 30 minutes per day, three for 30 to 60 minutes per day, and a score of four for more than 1 hour per day.

In obtaining extent of participation values for subjects the points for question 43 were multiplied with the points for question 44. This product was labeled extent of participation, and across all subjects it had a mean of 7.69 and a standard deviation of 4.43. Four groups were determined. Low active, with extent of participation values less than 5, medium low active with values between 5 and 7 , medium high active with values between 8 and 10, and finally high active with values greater than 10 .

Females. The factor means and standard deviations for the female subjects are in Table 12. There were 35 females in the low active group, 17 in the medium low group, 38 in 
Table 12

Extent of Participation: From Low to High Active

FEMALES

L. Act.
$(n=35)$$\quad \begin{gathered}\text { M.L. Act. } \\ (n=17)\end{gathered} \quad \begin{gathered}\text { M. A. Act. } \\ (n=38)\end{gathered} \quad \begin{aligned} & \text { H. Act. } \\ & (n=44)\end{aligned}$

Sport

$\begin{array}{lllll}M & 12.46 & 14.18 & 13.61 & 15.14\end{array}$

\begin{tabular}{lrrrrr} 
& S.D. & 4.02 & 3.81 & 4.39 & 5.08 \\
\cline { 2 - 6 } Condition & S.D. & 3.32 & 3.06 & 3.51 & 3.77 \\
\cline { 2 - 6 } Body & S.D. & 4.39 & 3.12 & 3.92 & 4.56 \\
\cline { 2 - 6 } & M & 14.69 & 15.24 & 15.53 & 16.39 \\
\multirow{2}{*}{ Strength } & S.D. & 4.49 & 2.19 & 3.08 & 4.47 \\
\cline { 2 - 6 } & M & 14.34 & 16.41 & 16.00 & 17.52 \\
PSW & S.D. & 4.21 & 3.00 & 3.87 & 3.93 \\
\cline { 2 - 6 } & M & 31.83 & 35.88 & 33.11 & 34.27 \\
\multirow{2}{*}{ SEI } & S.D. & 6.16 & 3.87 & 4.43 & 4.61 \\
\hline
\end{tabular}

the medium high group, and 44 in the high active group. An examination of Table 12 indicates that subscale values increased in a stepwise progression from the low active to the high active group only for the physical condition and strength scales. For all the other scales the medium low active group and the medium high active group had similar means. 
Table 13

Subject Classification: From Low to High Active FEMALES

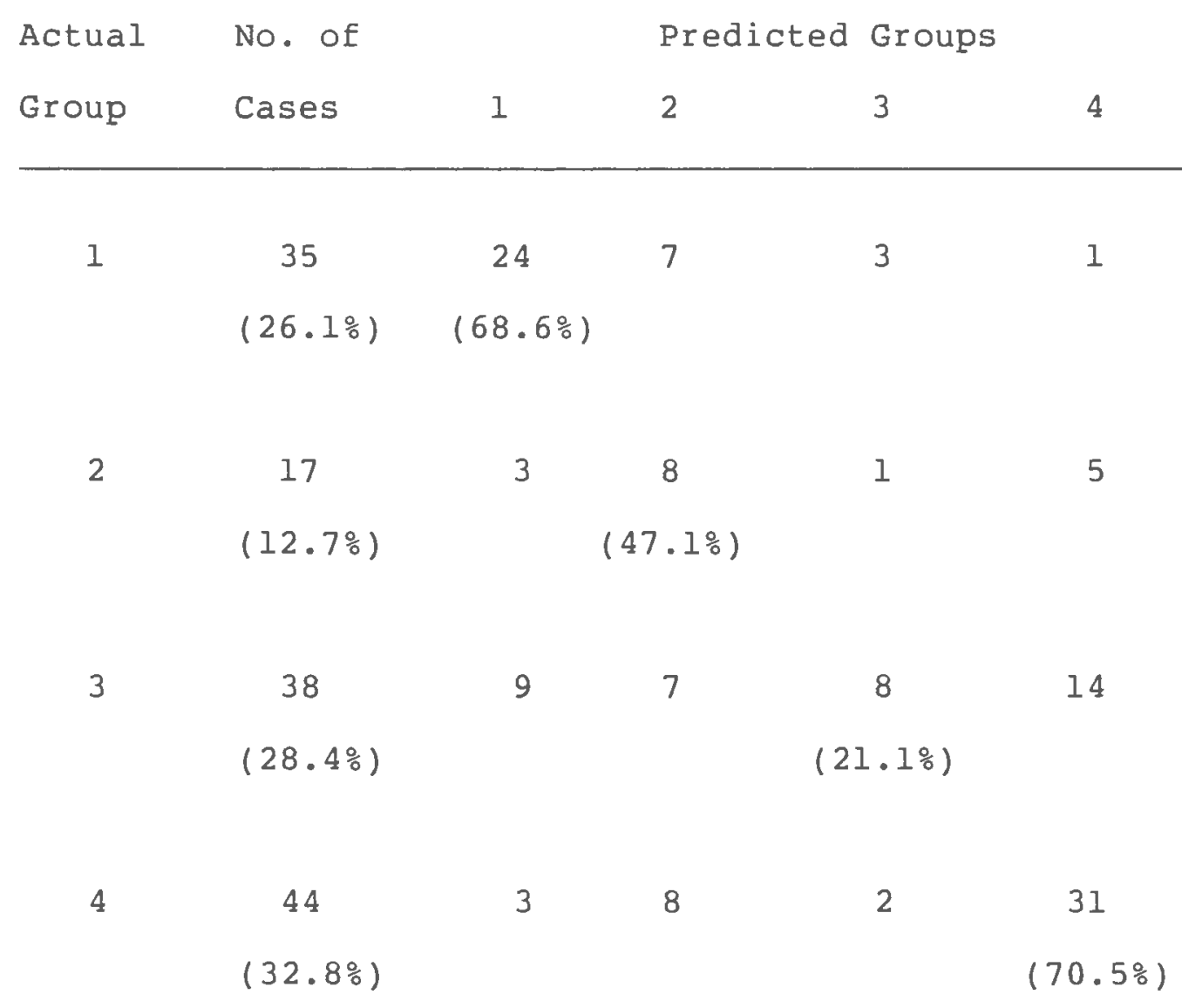

Percent Correctly Classified - 52.99\%

A stepwise discriminant analysis was completed to select the factors with the best predictive abilities in classifying the female exercisers. The analysis selected four variables. 
The first was physical condition, the second was global selfesteem, followed by strength, and finally physical selfworth. The standardized betas for the four scales selected were $1.31,-0.33,-0.34$, and 0.03 , respectively. classification of subjects can be found on Table 13. The equation was able to correctly classify $52.99 \%$ of all female exercisers. All groups were predicted better than the base rate except for the medium high active group. For this group only $21.1 \%(8 / 38)$ were correctly

predicted, where a random placement would have a $28.4 \%(38 / 134)$ success rate. Fourteen of the 38 subjects were predicted to be highly active by the equation.

Males. The means and standard deviations for the males are in Table 14. An examination of Table 14 reveals that only the physical condition scale showed progressive increases from the low active to high active groups. For all other scales the medium low group and the medium high group had similar means.

A stepwise discriminant analysis was completed to ascertain the scales best able to predict physical activity. The analysis extracted three variables: physical condition, attractive body, and strength. The standardized betas for the three were, $1.24,-0.52$, and 0.01 , respectively. Sports competence, physical self-worth, and global self-esteem were not selected as significant predictors. Table 15 shows the 
Table 14

Extent of Participation: From Low to High Active

MALES

\begin{tabular}{|c|c|c|c|c|c|}
\hline & & $\begin{array}{l}\text { L. Act. } \\
(n=36)\end{array}$ & $\begin{array}{c}\text { M.L. Act. } \\
(\mathrm{n}=14)\end{array}$ & $\begin{array}{c}\text { M.H. Act. } \\
(n=22)\end{array}$ & $\begin{array}{l}\text { H. Act. } \\
(n=30)\end{array}$ \\
\hline \multirow{2}{*}{ Spor } & $\mathbf{M}$ & 14.67 & 15.14 & 14.73 & 18.03 \\
\hline & S.D. & 4.44 & 4.57 & 3.45 & 3.63 \\
\hline \multirow{2}{*}{\multicolumn{2}{|c|}{ Condition }} & 13.58 & 15.64 & 17.23 & 19.80 \\
\hline & & 2.96 & 3.89 & 3.02 & 3.31 \\
\hline \multirow{2}{*}{ Body } & $M$ & 15.22 & 15.21 & 14.77 & 17.73 \\
\hline & S.D. & 3.70 & 3.77 & 3.62 & 3.63 \\
\hline \multicolumn{2}{|c|}{ Strength } & 14.78 & 16.86 & 15.45 & 17.80 \\
\hline & S.D. & 3.42 & 3.82 & 2.50 & 3.85 \\
\hline \multirow{2}{*}{ PSW } & $M$ & 15.42 & 16.93 & 16.50 & 18.77 \\
\hline & S.D. & 3.25 & 3.50 & 3.32 & 3.66 \\
\hline \multirow{2}{*}{ GSE } & $M$ & 32.89 & 33.64 & 33.18 & 35.13 \\
\hline & S.D. & 4.38 & 3.88 & 3.87 & 5.57 \\
\hline
\end{tabular}

results of the predicted placement of male subjects into the four categories. The total percent of males that were properly classified was $51.96 \%$. All four groups were predicted well above the base rate for selection by random placement. These analyses can be interpreted as providing a degree of validity for self-perception variables, particularly as measured by the Fox scales, in predicting extent of 
exercise participation.

$$
\text { Table } 15
$$

Subject Classification: From Low to High Active

\section{MALES}

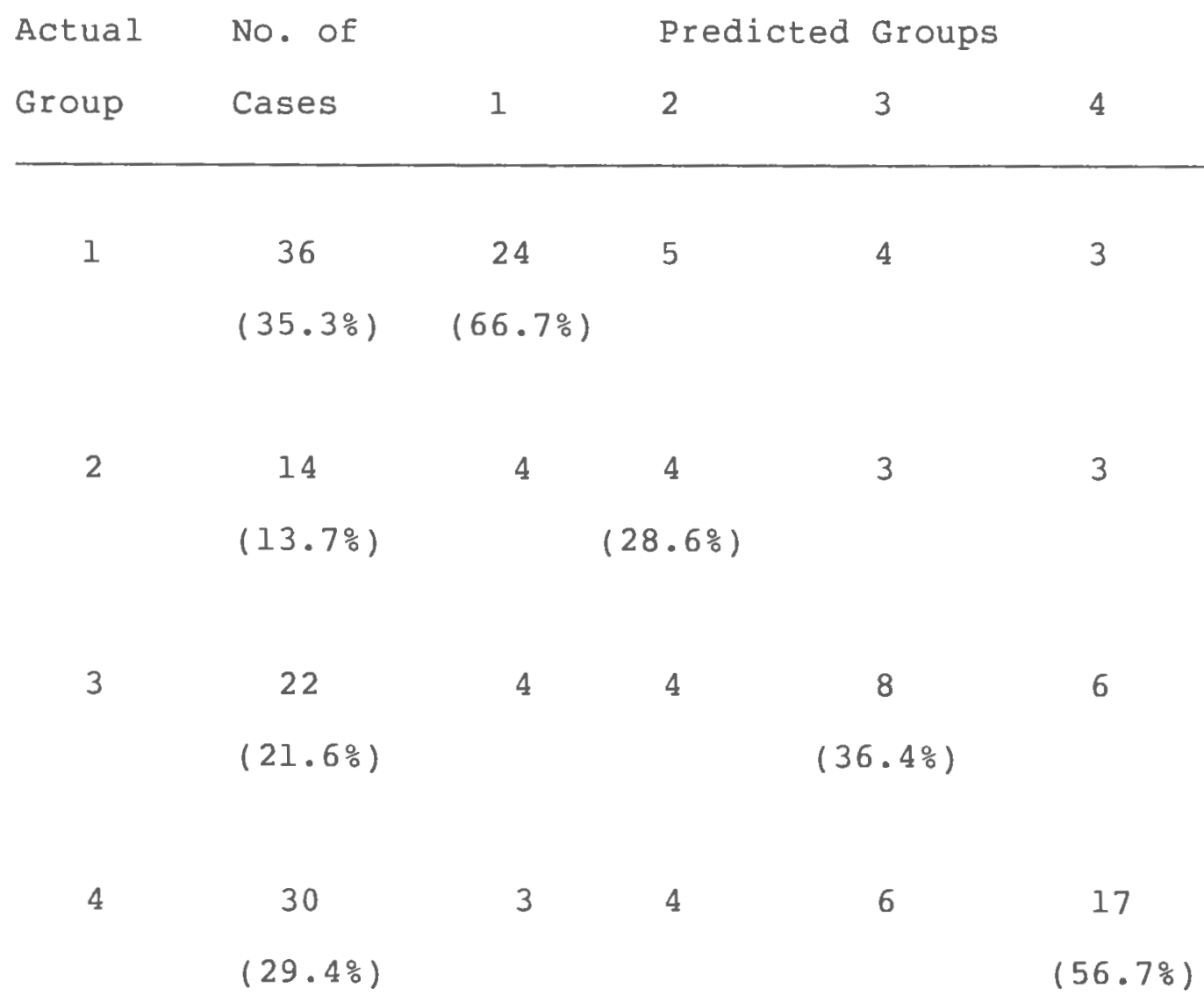

Percent Correctly Classified - 51.96\% 
Exercise Group Membership

The effects of organized exercise program participation on the PSPP scale scores were analyzed next. It was

hypothesized that subjects who participated in an organized fitness program would score higher on the Fox scales than would subjects from the general population. Additionally, the effect of sex on specific scale scores was examined. Initially, Pearson r coefficients were calculated to examine the relationship between age and the different PSPP scales. For all subjects, females and males, age was found to have a significant inverse relationship only with the sports competence scale $(r=-0.115, p<.03)$, and the strength scale( $r=-$ $0.131, p<.01)$. A further analysis of age was completed using age as a covariate in group/sex analyses. A $2 \times 2$ analysis of covariance was utilized which examined the main effects and interactions of exercise group membership and sex, with age being controlled for, on scale scores.

Table 16 exhibits the significant means for group and sex effects from the ANCOVA analysis. None of the PSPP scales showed any interaction effect. The condition scale, when age was controlled, showed a highly significant main effect of group membership $(\mathrm{F}=22.48, \mathrm{p}<.001)$. The strength scale was the only other scale to display a significant group membership effect $(F=5.22, p<.02)$. All other scales were found to have no significant group effect.

The sex effect, when age was controlled, was much more 
TABLE 16

Summary of ANCOVA Testing:

Means for Significant Group and Sex Effects

$\begin{array}{ll} & \text { Group } \\ \text { Members } & \text { Non-Members } \quad p\end{array}$

Sport

Condition

18.36

15.54

.001

Body

Strength

16.06

15.43

.02

PSW

Sex

Females

Males

$\mathrm{p}$

Sport

13.43

15.60

.001

Condition

Body

14.82

15.86

.03

Strength

15.10

16.15

.01

PSW

15.69

16.89

.01 
prevalent. All PSPP scales except for the condition scale were found to be significant. The scale with the most significant sex effect was sport competence $(F=17.66, p<.001)$. Strength and PSW also should significant sex effects, as well as $\operatorname{body}(F=7.93, \quad p<.01 ; \quad F=6.97, \quad p<.01 ; \quad F=5.05, \quad p<.03$, respectively).

These results indicate that only the means for the condition, and strength scales were organized fitness members significantly greater than non-members. Meanwhile, the males had significantly higher means than the females on all scales except for the condition scale. There were no significant interaction effects with this population.

\section{Summary of Criterion Validity Testing}

Criterion validity concerns itself with convergent and discriminant validity. It is necessary to demonstrate what criteria a test should relate to(convergent validity), and also to demonstrate that a test fails to relate to criteria it would not be expected to relate to(discriminant validity). In all analyses it would be hypothesized that the scales which would be most related to participation included condition, strength, attractive body, and the more general physical selfworth. The scales that were thought to have a poor relationship with participation were, sports competence, and global self-esteem. In the present study three criterion measures were utilized. These were self-reported exercisers 
versus non-exercisers, self-reported extent of exercise participation, and organized exercise group membership versus non-membership.

For the self-reported exercise participation analysis, condition was the scale with the most significant contribution in predicting participation, with both females and males. Strength was also significant in predicting participation for both sexes. For the male subjects, physical self-worth was a third scale that showed some ability to predict participation. For the female subjects, the condition and strength scales displayed convergent validity by correctly classifying $84.6 \%$ of the subjects in the appropriate group. For the male subjects, condition, strength and physical selfworth all showed convergent validity by properly categorizing 78.3\% of the males. Sports competence and global self-esteem exhibited discriminant validity by showing no ability to predict participation, for either sex.

For the subjects who labeled themselves exercisers, and were further categorized by extent of participation, condition again displayed the most significant ability to predict participation, for both females and males. Global selfesteem, strength, and physical self-worth also were found to have some ability to predict participation for the female subjects. The four scales together were able to correctly classify $59.22 \%$ of the female subjects. For three out of the four specific extent of participation groups, the discriminant 
function equation was able to place subjects in the proper group at a rate that was better than chance.

The male subjects had only two scales besides condition that significantly contributed to predicting participation. One was attractive body, and the other was strength. These three scales were able to correctly classify $51.96 \%$ of the males, and the discriminant function equation was able to place subjects into the correct category at a rate that was better than chance.

For the extent of participation, condition and strength showed to be convergently valid for both males and females. Physical self-worth displayed signs of being valid but only for females, while attractive body did likewise for the males. Sports competence again demonstrated discriminant validity by not predicting extent of participation, as was expected.

For the group membership analysis, condition and strength illustrated significant relationships with prediction, thus displaying convergent validity. Also sports competence and global self-esteem displayed discriminant validity. Unfortunately, neither attractive body nor physical selfworth showed any signs of being convergently valid.

Based on the analyses above it was concluded that the PSPP, particularly with it's condition scale, is able to significantly predict exercise participation. Therefore, the null hypothesis that PSPP scales would not significantly predict levels of physical activity as reported by subjects 
is rejected.

\section{Discussion}

One of the significant outcomes of this present study has been the discovery that the attractive body scale and the physical self-worth scale are interdependent. Fox and Corbin(1989) designed their model(Appendix A) so that physical self-worth would be an intermediary between specific physical self-perceptions and global self-esteem. However, in this study, the attractive body scale and the physical self-worth scale were difficult to separate. These results can be found in several places. An indication of lack of independence was the high relationship between body and physical self-worth. Pearson r coefficients of .785 for females and .798 for males may be considered too large. These coefficients indicate that in these body-PSW relationships, the amount of variance unique to either construct was considerably less than the amount of variance shared by the constructs. Fox and Corbin(1989) also found somewhat large coefficients between body and physical self-worth. These authors obtained coefficients of .7l for females, and .74 for males. The correlation coefficients, however, were not the only place where the lack of independence is noticeable.

Principal component analyses showed that for both males and females attractive body items and physical self-worth items loaded onto the same component(Tables 6 and 7 ). This 
would indicate that the two scales were highly interrelated. Unfortunately, Fox and Corbin(1989) did not include physical self-worth items in their principal component analysis. These authors used only the four specific physical selfperceptions, believing that the PSW was a superordinate variable, and thus it was not necessary to include it in the analysis(Fox and Corbin, 1989). Because of this decision it is difficult to make any definite comparisons between their results and the results of this study. This study does show that for an older adult population there is a great deal of interdependence between the attractive body scale and the physical self-worth scale.

These results make it very difficult to clearly understand the relationship between the attractive body scale and the physical self-worth scale. The relationship between the three other specific physical self-perceptions and physical self-worth is identifiable, with the physical selfworth functioning as an intermediary factor between the specific self-perceptions and global self-esteem. Where the problem between body and PSW lies, however, is not exactly clear. One thing is definite, more research using this inventory is necessary, and when future research is attempted, it is recommended that either the PSW scale is not included or the scale is rewritten to produce a more independent scale. The physical self-worth scale was developed separately from the four specific self-perception scales of the PSPP 
inventory. Because of this, it may be desirable to redevelop the physical self-worth scale using the methods implemented in the development of the four specific physical self-perception scales.

Another inference that can be made is that possibly the more general physical self-worth scale does not exist for older adults. It may be that self-perceptions about physical activity for older adults makes it difficult to differentiate between attractive body and general physical self-worth. Physical self-worth, as theorized by Fox and Corbin(1989), may not be an important construct in older adults. Another possibility is that attractive body may be especially important to older adults. All these uncertainties about physical self-worth can only be answered with more research.

Despite these confounding results, for the most part this study offers support to the PSPP as a valid inventory, especially to the four specific physical self-perception scales. All four scales were found to be relatively independent of each other. The correlations between subscales(Table 3 ) show an average mean shared variance of $24 \%$ for females, and 30\% for males. The specific selfperception scales, plus the physical self-worth scale, all showed excellent internal validity. This indicates that the items in each scale are measuring that specific selfperception. Scale means were situated near the mid-range of scores, signifying that the responses were well distributed 
throughout the whole range of possible scores. There was relatively little skewness and kurtosis. This indicates that responses to the scales were quite close to a normal curve, avoiding clustering on either the high or low end of a scale.

All these results were very similar to the findings of the Fox and Corbin(1989) study. However, this present study does not offer much validity for the intermediary role of the physical self-worth component in the hierarchy. This study also does not substantiate the results from the Fox and Corbin study(1989) on the use of the physical self-worth scale with the other four subscales of the PSPP.

Criterion validity was established for the PSPP. The condition scale and the strength scale were found to have convergent validity. The condition scale produced the most significant relationship with exercise participation for both females and males. In fact, the scales were better predictors of exercisers and non-exercisers for older adults, as compared to what Fox and Corbin(1989) found with college-aged adults. In the stated participation analysis, $84.6 \%$ of the middleaged adult females were properly categorized, while $70.7 \%$ of the college-aged females were correctly classified. Likewise, for middle-aged males $78.3 \%$ were accurately placed, while 70.4\% of the college-aged males were properly categorized. Fox and Corbin(1989) also found condition to be the most dominant component in predicting participation.

When extent of participation, and group exercise 
membership were analyzed, condition still remained the dominant component in predicting participation. The other variables that displayed some convergent validity included strength, physical self-worth, and attractive body. Discriminant validity for the PSPP was demonstrated with the sports competence scale, which failed to predict any of the three exercise groups that were tested. The scale showed to have no significant ability in predicting participation. These results exhibit the criterion validity of the PSPP inventory, which again substantiate Fox's results.

This study demonstrated that although there is some difficulty separating attractive body and physical selfworth, there is an amount of evidence for a hierarchical model as proposed by Fox and Corbin(1989)(Appendix A). Tables 3 and 4 show that the specific physical self-perceptions were more highly related to physical self-worth than to global selfesteem. For the females, the correlations between the subscales and global self-esteem ranged between .564 and .247 , while the coefficients between the subscales and physical self-worth ranged between .785 and .548 . Similarly for the males, the coefficients between the subscales and global self-esteem ranged between .544 and .319, while the correlations between the subscales and physical self-worth ranged between .798 and .623 . These results indicate that the specific self-perception subdomains are more highly related to physical self-worth than they are to global self-esteem. 
This indicates that there is a stepwise progression from specific self-perceptions to global self-esteem. However, this study questions the ability of the PSW scale to act as the mediating variable within that progression.

There were also several interesting results from the organized fitness members and non-members analysis. The condition scale and the strength scale were the only two scales that fitness members scored significantly higher than non-members. Members had an average mean of 18.36 , while nonmembers had an average mean of 15.54 , for the condition scale, and a mean of 16.06 for members and 15.43 for non-members for the strength scale. For all the other scales the two groups were quite similar, with no significant differences between mean scores.

The differences between the sexes was also interesting. For all scales except for the condition scale the males scored significantly higher than the females. Sports competence had the largest difference, with the females having a mean of 13.41, and the males a mean of 15.60. It is believed that the validity of the present research lies in the fact that it was able to document results from an often neglected population. A majority of the research relies on college sophomores, but then tries to expand the results to include adults many years older. Therefore, this study has made a notable contribution to the older adult population, which is often a target population of testing new exercise habits, but 
rarely the target of research studies.

It is conceded that within the age span studied, 30 to 65, several subpopulations may exist. Future studies may wish to address the differences in physical self-perceptions within people between the ages of 30 and 65 . However, this study found a very slight age effect. The only two scales to show any significant age effect were the sports competence scale( $\mathrm{r}=-.115, \mathrm{p}<.03)$ and the strength scale

$(\mathrm{r}=-.131, \mathrm{p}<.01)$. This study was unable to show any significant age effect within the PSPP inventory, for the population studied.

To some extent it is understandable why college populations are the most often studied. They are easily accessible, and sample sizes are always large. In this study many hours were spent chasing after subjects, trying to retrieve completed questionnaires. Also, in an effort to give the results stronger validity it was necessary to collect a large number of subjects, which with an adult population is not always the easiest of feats.

\section{Practical Applications}

The PSPP, especially the four specific physical selfperception scales, received a degree of validity with an older adult population. This suggests that the scales could be used in adult fitness programs. The scales examine specific physical self-perceptions, which can be used to determine an 
individualized training program that fits the self-perceptions of each individual. The inventory could also be used to assess whether self-perceptions change with the introduction of exercise. Finally, because the scales have also displayed criterion validity in their ability to predict and classify exercisers and non-exercisers, this information could also help adult fitness programs analyze participants. Analysis would help administrators distinguish between exercisers and non-exercisers, and as stated above, develop specific programs for each individual to expand on those perceptions which appear to be important for a specific individual.

It is recommended that if the PSPP is employed with an older adult population again, that researchers be warned about the inconsistencies of the physical self-worth scale. Researchers should realize that there is evidence of overlapping between the PSW scale and the attractive body scale, and some question as to were the scale fits into the model. Using the PSW scale with the attractive body scale may confound the expected intermediary effect of physical self-worth component.

\section{Implications for Future Research}

This study used a very small sub-group of the adult population. However, this study offers new information on a frequently forgotten population. Adults over the age of twenty-one are usually not included in research projects 
because of the difficulty in sampling. This study has offered some new insight into this population. However, for this information to be beneficial more studies with older adults must be attempted.

Because of the confounding results found between physical self-worth and attractive body, it may be best to attempt to rewrite both scales to make them more independent of each other. It is recommended that corrections begin with the physical self-worth scale, since Fox and Corbin(1989) did not develop the scale in the same manner as the four specific self-perception scales. Also, more research must be completed with older adults to determine if in fact physical self-worth is an intermediary variable between specific physical selfperceptions and global self-esteem. 


\section{References}

Allen, S.J. and Hubbard, R.(1986). Regression equations for the latent roots of random data correlation matrices with unities on the diagnol. Multivariate Behavioral Research, 21, 393-398.

Anderson, L.W.(1981). An examination of the nature of change in academic self-concept. In M.D. Lynch, A.A. Norem Hebeisen \& K.J. Gergen(Eds.), Self-concept: Advances in Theory and Research(pp. 273-282). Cambridge, MA: Ballinger Publishing Company.

Brown, E.Y., Morrow, J.R., and Livingston, S.M.(1982). Selfconcept changes in women as a result of training. Journal of Sport Psychology, 4, 354-363.

Byrne, B.M. and Shavelson, R.J.(1986). On the structure of adolescent self-concept. Journal of Educational Psychology, 78, 474-481.

Combs, A.W.(1981). Some observations on self-concept research and theory. In M.D. Lynch, A.A. NoremHebeisen \& K.J. Gergen(Eds.), Self-concept: Advances in theory and research (pp. 5-16). Cambridge, MA: Ballinger Publishing Company.

Cronbach, L.J.(1960). Essentials of psychological testing ( 2 nd ed.). New York: Harper and Row.

Dishman, R.K.(1978). Aerobic power, estimation of physical ability, and attraction to physical activity. Research Quarterly, 49, 285-292.

Dishman, R.K., Sallis, J.F., and Orenstein, D.R.(1985). The determinants of physical activity and exercise. Public Health Report, 100, 158-171.

Ferguson, G.A.(1966). Statistical analysis in psychology and education. New York: McGraw-Bill Book Company.

Fernhall, B. and Ausmus, J.L.(1987). Influence of selfreported activity on selected physiological variables. Medicine and Science in Sport and Exercise, 19, s23. (abstract)

Fleming, J.S. and Watts, W.A.(1980). The dimensionality of self-esteem: Some results for a college sample. Journal of Personality and Social Psychology, 39, 921-929. 
Fleming, J.S. and Courtney, B.E.(1984). The dimensionality fo self-esteem: II. Hierarchical facet model for revised measurement scales. Journal of Personality and Social Psychology, 46, 404-421.

Fox, K.R.(1988a). The child's perspective in physical education part 5: The self-esteem complex. British Journal of Physical Education, 19, 247-252.

Fox, K.R.(1988b). The self-esteem complex and youth fitness. Quest, $40,230-246$.

Fox, K.R. and Corbin, C.B.(1989). The physical selfperception profile: Development and preliminary validation. Journal of Sport and Exercise Psychology. $11,408-430$.

Fox, K.R., Corbin, C.B., and Couldry, W.H.(1985). Female physical estimation and attraction to physical activity. Journal of Sport Psychology, 7, 125-136.

Gale, J.B., Eckhoff, W.T., Mogel, S.F., and Rodnick, J.E.(1984). Factors related to adherence to an exercise program for healthy adults. Medicine and Science in Sports and Exercise, 16, 544-549.

Gecas, V. and Mortimer, J.T.(1987). Stability and change in the self-concept from adolescence to adulthood. In T. Honess and $K$. Yardley(Eds.). Self and identity: Perspectives across the lifespan(pp. 265-286). New York: Routledge and Kegan Paul.

Guilford, J.P. and Fruchter, B.(1973). Fundamental statistics in psychology and education. New York: McGraw-Hill Book Company.

Harter, S.(1982). The perceived competence scale for children. Child Development, 53, 87-97.

Harter, S.(1983). Developmental perspectives on the selfesteem. In E.M. Hetherington(Ed.), P.H. Mussen(Series Ed.), Handbook of child psychology(Vol. 4): Socialization, personality, and social development(pp. 275-385). New York: Wiley.

Harter, S.(1986). Process underlying the construction, maintenance, and enhancement of the self-concept in children. In J. Suls and A.G. Greenwald(Eds.), Psychological perspectives on the self(Vol. 3)(pp. 137181). Hillsdale, New Jersey: Lawrence Erlbaum Associates. 
Horn, J.L.(1965). A rationale and test for the number of factors in factor analysis. Psychometrika, 30, 179185.

Leonardson, G.R.(1977). Relationship between self-concept and perceived physical fitness. Perceptual and Motor Skills, 44,62 .

Leonardson, G.R. and Gargiulo, R.M.(1978). Self-perception and physical fitness. Perceptual and Motor Skills, 46, 338 .

Marsh, H.W. (1987). The hierarchical structure of self-concept and the application of hierarchical confirmatory factor analysis. Journal of Educational Measurement, 24, 1739 .

Marsh, H.W. and Shavelson, R.(1985). Self-concept: Its multifaceted, hierarchical structure. Educational Psychologist, 20, 107-123.

Neale, D.C., Sonstroem, R.J. and Metz, K.F.(1969). Physical fitness, self-esteem, and attitudes toward physical activity. The Research Quarterly, 40, 743-749.

Rosenberg, M.(1965). Society and the adolescent self-image. Princeton, NJ: Princeton University Press.

Rosenberg, M.(1979). Conceiving the self. New York: Basic Books, Inc.

Rosenberg, M. and Kaplan, H.B.(Eds.).(1982). Social psychology of the self-concept. Arlington Heights, IL: Harlan Davidson, Inc.

Shavelson, R.J. and Bolus, R.(1982). Self-concept: The interplay of theory and methods. Journal of Educational Psychology, 74, 3-17.

Shavelson, R.J., Hubner J.J. and Stanton, G.C.(1976). Selfconcept: Validation of construct interpretations. Review of Educational Research, 46, 407-441.

Sonstroem, R.J.(1974). Attitude testing examing certain psychological correlates of physical activity. The Research Quarterly, 45, 93-103.

Sonstroem, R.J.(1976). The validity of self-perceptions regarding physical and athletic ability. Medicine and Science in sports, 8, 126-132. 
Sonstroem, R.J.(1978). Physical estimation and attraction scales: Rationale and research. Medicine and Science in Sports, 10, 97-102.

Sonstroem, R.J.(1982). Exercise and self-esteem: Recommendations for expository research. Quest, 33, 124-139.

Sonstroem, R.J.(1984). Exercise and self-esteem. In R. Terjung(Ed.). Exercise and Sport Sciences Reviews, 12, 123-155.

Sonstroem, R.J. and Morgan, W.P.(1989). Exercise and selfesteem: Rationale and model. Medicine and Science in Sports and Exercise, 21, 329-337.

Thornton, B., Ryckman, R.M., Robbins, M.A., Donolli, J. and Biser, G.(1987). Relationship between perceived physical ability and indices of actual physical fitness. Journal of Sport Psychology, 9, 295-300.

Velicer, W.F.(1976). Determining the number of components from the matrix of partial correlations. Psychometrika, $41,321-327$.

Young, M.L.(1985). Estimation of fitness and physical ability, physical performance, and self-concept among adolescent females. Journal of Sports Medicine, 25, $144-150$.

Zwick, W.R. and Velicer, W.F.(1985). A comparison of five rules for determining the number of components in data sets. Unpublished manuscript. (not seen) 
APPENDIX A 


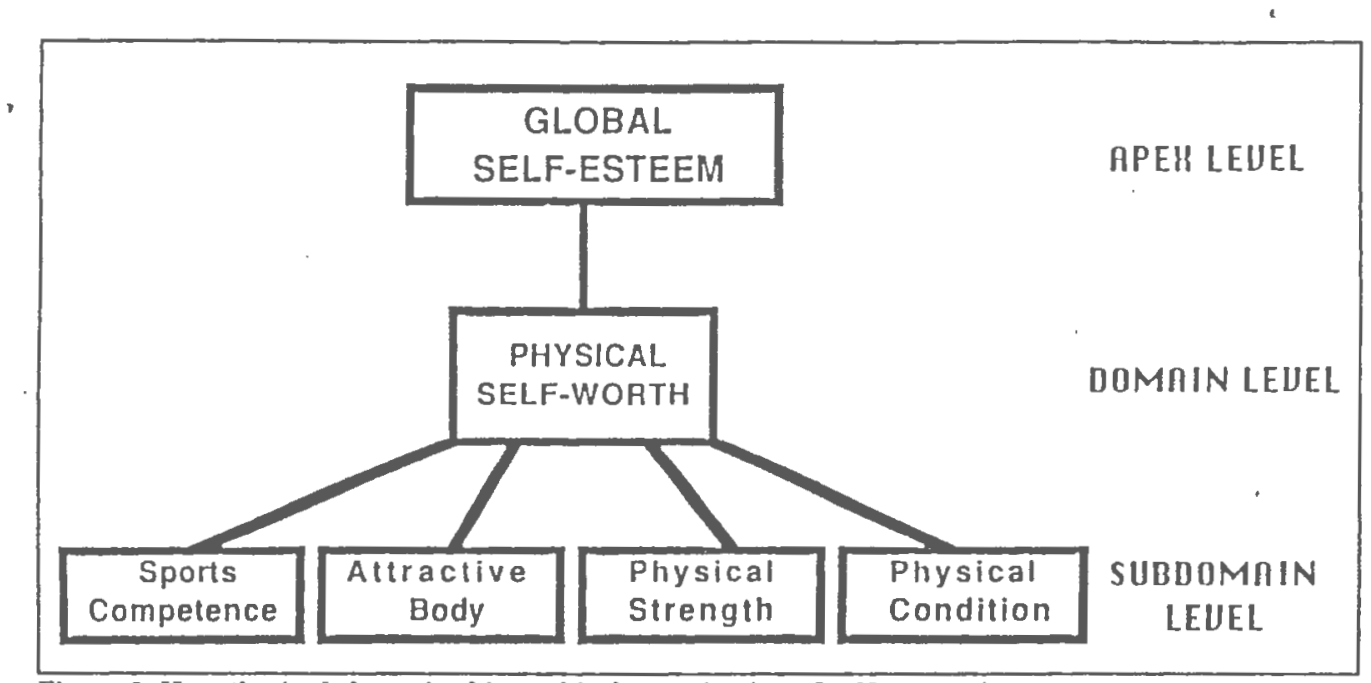

Figure 3. Ilypothesized three-tier hierarchical organization of self-perceptions. (Reported with permission of Human Kinetics, Inc.) 
APPENDIX B 


\section{INFORMED CONSENT - BEHAVIORAL DATA}

You are being asked to answer some questions on the following pages. The purpose of these questions is to develop some ideas about what people think about themselves in regard to physical activity.

It should be emphasized that there are no right or wrong, no good or bad responses to the questions you are answering. please answer each item as honestly as you can.

Data will remain strictly confidential. All data will be coded and will not be identifiable by name. You do not have to complete these inventories and you may refuse to do so at any time. Please feel free to ask any questions you may have.

\section{Voluntary Consent}

Date

The purpose of my participation in these procedures has been explained to me. I freely consent to participate. I understand that I am not required to participate and that I may stop participation at any time.

\section{(Signature)}


APPENDIX C 


\section{DIRECTIONE}

on the followling pages you wlil find approximately Eorty-elve questions which deal with your self-perceptions regarding exerclse. Please read each question thoroughly and glve, the answer which best applies to you. Please place your answers on the computer sheet whlch was given to you.

1. Flip the answer sheet over to side two and Elil out only the sex and birth date information in the upper left hand corner of the answer sheet. Once this is completed fllp the answer sheet back over to side one.

2. DO NOT WRITE YOUR NAME on any of the sheets to keep all responses as confidentlal as possible.

3. Read each question carefully and then flli-in the approprlate circle on the ANSWER SHEET that matches the response you selected.

4. Fill-in ONLY ONE LETTER on the answer sheet for each question.

5. The last question is a short answer. Please write out your response directly onto the questionnalre.

6. If you have any questions at any polnt please stop and ask for clarlelcation.

Thank you for taking the time to fill out the questionnaire. your effort and support are greatly appreclated.

PLEASE RROCEED TO THE DURECTIONS AT THE TOR OE THE NEXT RAGE. 


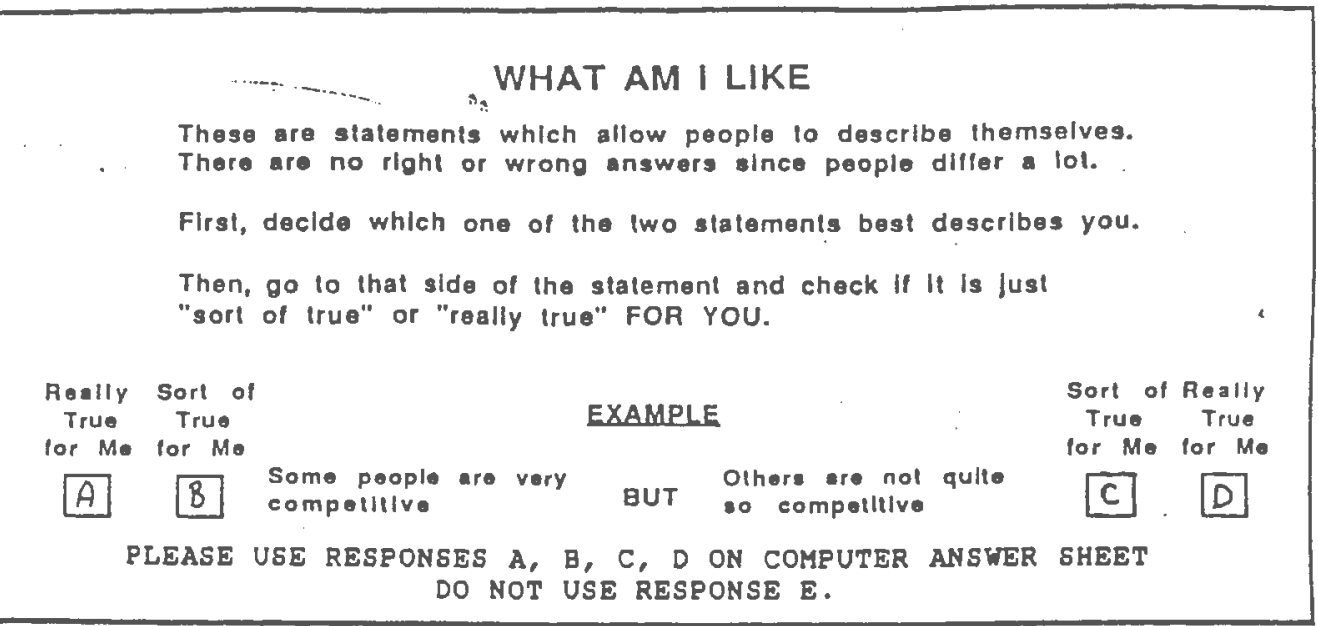

\begin{tabular}{|c|c|c|c|c|c|c|c|}
\hline 1. & $A$ & $B$ & $\begin{array}{l}\text { Some people feel that } \\
\text { they are not very } \\
\text { good whon it comed } \\
\text { to playlng eports }\end{array}$ & BUT & $\begin{array}{l}\text { Others teel that they } \\
\text { ore really good at } \\
\text { just mbout every } \\
\text { sport }\end{array}$ & $\bar{c}$ & D \\
\hline 2. & $A$ & $B$ & $\begin{array}{l}\text { Some poople are not } \\
\text { very confldent bout } \\
\text { thelr level of physical } \\
\text { conditloning and fltnegs }\end{array}$ & BUT & $\begin{array}{l}\text { Others lways feel } \\
\text { confldent that they } \\
\text { malntaln oxcellent } \\
\text { condltioning and fitnos }\end{array}$ & $C$ & $D$ \\
\hline 3. & $A$ & 8 & $\begin{array}{l}\text { Some poople fool that } \\
\text { compared to most, they } \\
\text { have on attractlve body }\end{array}$ & BUT & $\begin{array}{l}\text { Others toel that compared } \\
\text { to most, thelr body is } \\
\text { not quite so ettractlve }\end{array}$ & $C$ & D \\
\hline 4. & $A$ & $B$ & $\begin{array}{l}\text { Some people feol that } \\
\text { they re physlcally } \\
\text { stronger than most } \\
\text { people of thelr sex }\end{array}$ & BUT & $\begin{array}{l}\text { Others teol that they } \\
\text { lack physlcal strength } \\
\text { compared to most athers } \\
\text { of thelr sex }\end{array}$ & $C$ & $D$ \\
\hline 5. & $A$ & $B$ & $\begin{array}{l}\text { Some people feel } \\
\text { extremely proud of who } \\
\text { thoy re and what they } \\
\text { con do physleslly }\end{array}$ & BUT & $\begin{array}{l}\text { Others are sometimes } \\
\text { nol qulte so proud of } \\
\text { who they ore phyelcally }\end{array}$ & $C$ & $D$ \\
\hline 6. & $A$ & $B$ & $\begin{array}{l}\text { Some people feel that } \\
\text { they are among the best } \\
\text { when it comes lo } \\
\text { athlotle abllily }\end{array}$ & BUT & $\begin{array}{l}\text { Others leal that they } \\
\text { are not emong the most } \\
\text { able when It comes to } \\
\text { athletles }\end{array}$ & $C$ & $D$ \\
\hline
\end{tabular}




\begin{tabular}{|c|c|c|c|c|c|c|c|}
\hline & $\begin{array}{l}\text { Really } \\
\text { True }\end{array}$ & $\begin{array}{c}\text { Sort of } \\
\text { True }\end{array}$ & & & & $\begin{array}{l}\text { Sor of } \\
\text { True }\end{array}$ & $\begin{array}{c}\text { Really } \\
\text { True } \\
\text { lor Me }\end{array}$ \\
\hline & lor Me & for Me & $\mathrm{A}:$ & & 1 & & \\
\hline 7. & A & $B$ & $\begin{array}{l}\text { Some people meko certaln } \\
\text { they take pert in some } \\
\text { form of regular vigorous } \\
\text { physlcal exerelse }\end{array}$ & BUT & $\begin{array}{l}\text { Others don't olten } \\
\text { manage to keep up } \\
\text { regular vigorous } \\
\text { phyolcal exerclee }\end{array}$ & C & $D$ \\
\hline 8. & $A$ & B & $\begin{array}{l}\text { Some people feel thet } \\
\text { they have difflculty } \\
\text { mainlaining an attrectlve } \\
\text { body }\end{array}$ & BUT & $\begin{array}{l}\text { Others feel that they } \\
\text { are easlly ble to keep } \\
\text { thelr bodles looking } \\
\text { ettrectlve }\end{array}$ & C & D \\
\hline 9. & A & 8 & $\begin{array}{l}\text { Some people feel that } \\
\text { their muscles are much } \\
\text { atronger than most } \\
\text { others of their sex }\end{array}$ & ${ }^{\text {BUT }}$ & $\begin{array}{l}\text { Others feel that on the } \\
\text { whole thelr muscies are } \\
\text { not qulte so strong as } \\
\text { most others of their sex }\end{array}$ & C & $D$ \\
\hline 10. & $A$ & $B$ & $\begin{array}{l}\text { Some people are same- } \\
\text { tlmea not so happy with } \\
\text { the way they are or what } \\
\text { they can do physically }\end{array}$ & BUT & $\begin{array}{l}\text { Othere glways leol } \\
\text { happy aboul the kind } \\
\text { of person they are } \\
\text { phyelcally }\end{array}$ & c & D \\
\hline 11. & $A$ & $B$ & $\begin{array}{l}\text { Some people ere not quite } \\
\text { so conlldent when it } \\
\text { comes to laking part in } \\
\text { sports actlvitles }\end{array}$ & BUT & $\begin{array}{l}\text { Othera are among the } \\
\text { most confldent when } \\
\text { It comes to taking part } \\
\text { In sports activilles }\end{array}$ & C & ( \\
\hline 12. & $A$ & $\bar{B}$ & $\begin{array}{l}\text { Some people do not } \\
\text { usualiy have a high level } \\
\text { of elamine and fliness }\end{array}$ & BUT & $\begin{array}{l}\text { Others alway malnialn } \\
\text { a high level of etamina } \\
\text { and flinees }\end{array}$ & C & $D$ \\
\hline 13. & $A$ & $B$ & $\begin{array}{l}\text { Some people foel } \\
\text { embarrasaed by thelr } \\
\text { bodles when It comes lo } \\
\text { wearing fow elothes }\end{array}$ & BUT & $\begin{array}{l}\text { Others do nol feel } \\
\text { embarrussed by thelr } \\
\text { bodles when it comes } \\
\text { wouring fow clothes }\end{array}$ & C & $D$ \\
\hline 14. & $A$ & $B$ & $\begin{array}{l}\text { When it comes lo sltual- } \\
\text { lons requirlag stength } \\
\text { some people ore one of } \\
\text { the flrst to tep forward }\end{array}$ & BUT & $\begin{array}{l}\text { When it comies to sltuat- } \\
\text { lone requiring tienglh } \\
\text { gome people are one of } \\
\text { the iast to step forward }\end{array}$ & - & $I$ \\
\hline 15. & $A$ & $B$ & $\begin{array}{l}\text { When it comes to the } \\
\text { physical side of them- } \\
\text { selves some people do } \\
\text { nol feel very confldent }\end{array}$ & BUT & $\begin{array}{l}\text { Others seem to have a } \\
\text { reat senee of confidence } \\
\text { in the physlcal side of } \\
\text { inemanives }\end{array}$ & C & $D$ \\
\hline 16. & A & B & $\begin{array}{l}\text { Some people feol that they } \\
\text { are always one of the best } \\
\text { when it comes to jolning } \\
\text { in sports sclivilles }\end{array}$ & BUT & $\begin{array}{l}\text { Others leel that they } \\
\text { ere nol one of the best } \\
\text { when it comes to loining } \\
\text { In eports actlviltios }\end{array}$ & 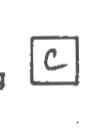 & $D$ \\
\hline
\end{tabular}




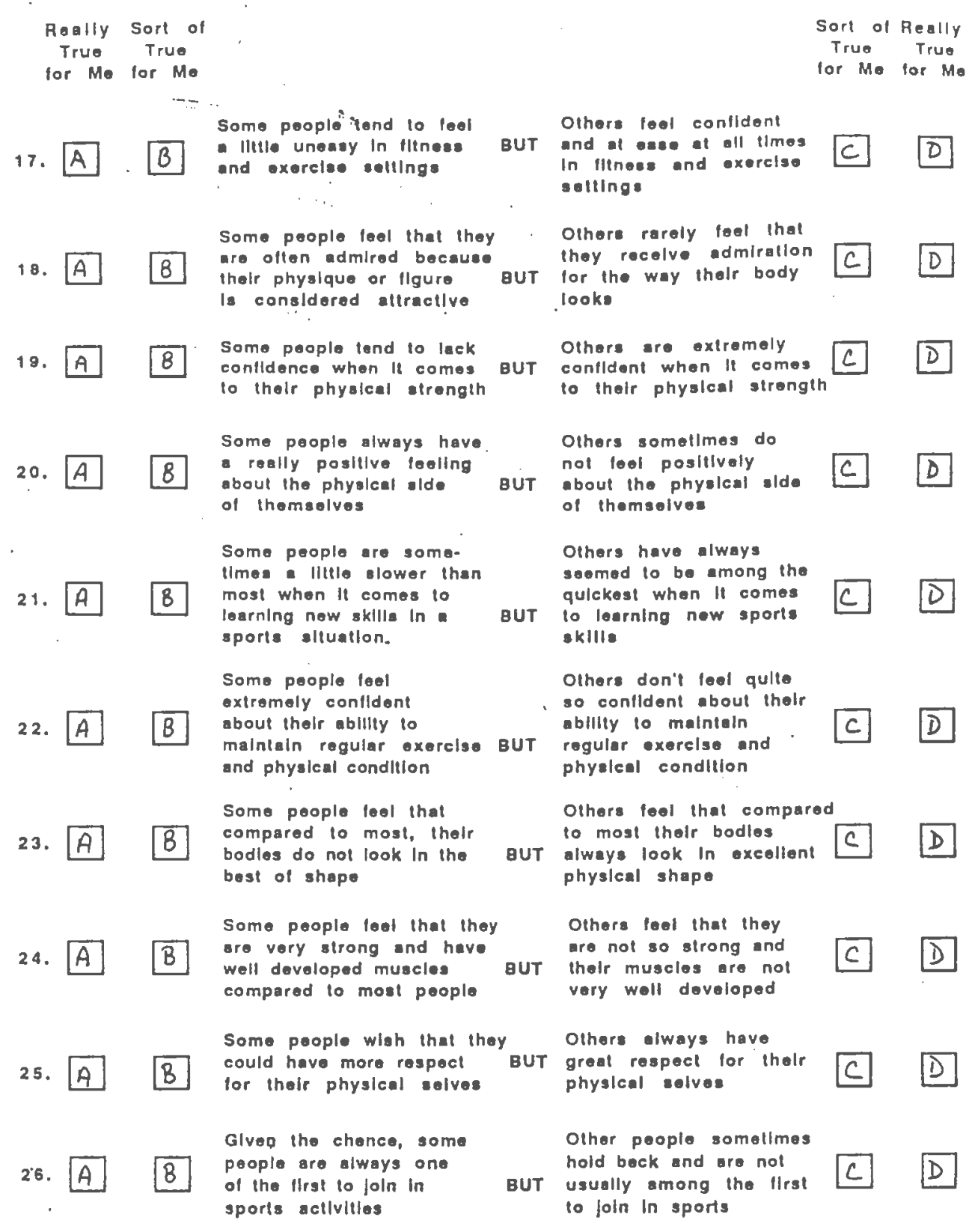


Really Sort ol
True True
for Me for Me

$\cdots+\cdots$
,

Some people teal thet

27. $A$

[B]. liway mainieln high

alway melnieln a high

lovel of physlcal, condilloning

Some people are

28. $A$ B extromely confldent

ebout the appearance

of their body

Some people leal that

29. $A$ they re not as good as sliuallong dealling with sliuallons requiring physlcal strength

Some people feel

30. $A$

the kind satislled with

the kind of person they
are physlcally

Sort of Aeally

Trua True

lor Me lor Me

Othera teot that compered

to moet thelr level of

physlcal condlitoning is

not usually so hlgh

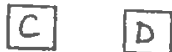

Others are a Illlle

self-coneclous boul

BUT the eppearance of

their bodles

$C D$

Other foel that they are emong the best at deallng with sltuallons whlch require physlcal eirangih

Others comelimes leel

- Iltlle dlsalisfled

BUT with thelr physlcat

selves

C $D$ 


\section{WHAT DO I FEEL ABOUT MYSELF IN GENERAL}

PLEASE ENTER THE MOST APPROPRIATE RESPONSE FOR YOU ON THE COMPUTER ANSWER SHEET

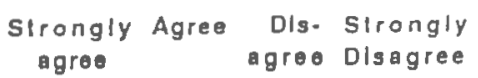

31. On the whole, I am satistied with myself

$\begin{array}{llll}A & B & C & D\end{array}$

32. At limes I think that I am no good at all

$\begin{array}{llll}A & B & C & D\end{array}$

33. I teel that I have a number of good quallites

$\begin{array}{llll}A & B & C & D\end{array}$
34. I am able to do things as well as most other
people

$\begin{array}{llll}A & B & C & D\end{array}$

35. I leel that I do not have much to be proud of $A \quad B \quad C \quad C$

36. I cerlainly leel useless at limes

$A \quad B \quad C \quad D$

37. I feel that I am a person of worth, at least $A \quad B \quad$ C $\quad D$ on an equal plane with olliers

38. I wish I could have more respect for myself $A$ B $\quad C \quad D$

39. All in all, I am inclined to feel that I am a $\quad A \quad B \quad$ C $\quad D$ failure

10. I lake a positive attitude loward myself

$A \quad B \quad C \quad D$


For questians $41,42,43$, and 44 please marl the $=i r=1$ e an the answer sheet whigh ispresponds with the letter sf the answer whili you feel best represents you.

41. Dï yau exerise requlary:
A. Yes
B. No

42. For how many years have you been exerising?
A. 1 month tis 1 year
B. 1 year to 3 years
E. 3 years ta 5 years
D. over 5 years

43. How many days per week do you exierise?
A. 1 day per weet:
8. 2 days per week.
E. 3 days per week:
D. mire than 3 days per week

44. How many minutes per day do you exer:ise?
A. less than 20 minutes per day
B. 20 to 30 minutes per day
C. 30 to 60 minutes per day
D. more than 1 hisur per day

45. Please list on this sheet the names af the activities that you participate in regularly. 


\section{Bibliography}

Allen, S.J. and Hubbard, R.(1986). Regression equations for the latent roots of random data correlation matrices with unities on the diagnol. Multivariate Behavioral Research, 21, 393-398.

Anderson, L.W. (1981). An examination of the nature of change in academic self-concept. In M.D. Lynch, A.A. Norem Hebeisen \& K.J. Gergen(Eds.), Self-concept: Advances in Theory and Research (pp. 273-282). Cambridge, MA: Ballinger Publishing Company.

Brown, E.Y., Morrow, J.R., and Livingston, S.M. (1982). Selfconcept changes in women as a result of training. Journal of Sport Psychology, 4, 354-363.

Byrne, B.M. and Shavelson, R.J.(1986). On the structure of adolescent self-concept. Journal of Educational Psychology, 78, 474-481.

Combs, A.W. (1981). Some observations on self-concept research and theory. In M.D. Lynch, A.A. Norem-Hebeisen \& K.J. Gergen(Eds.), Self-concept: Advances in theory and research (pp. 5-16). Cambridge, MA: Ballinger Publishing Company.

Cronbach, L.J.(1960). Essentials of psychological testing (2nd ed.). New York: Harper and Row.

Dishman, R.K.(1978). Aerobic power, estimation of physical ability, and attraction to physical activity. Research Quarterly, 49, 285-292.

Dishman, R.K., Sallis, J.F., and orenstein, D.R. (1985). The determinants of physical activity and exercise. Public Health Report, 100, 158-171.

Ferguson, G.A.(1966). Statistical analysis in psychology and education. New York: McGraw-Hill Book Company.

Fernhall, B. and Ausmus, J.L.(1987). Influence of selfreported activity on selected physiological variables. Medicine and science in sport and Exercise, 19, s23. (abstract)

Fleming, J.S. and Watts, W.A. (1980). The dimensionality of self-esteem: Some results for a college sample. Journal of Personality and Social Psychology, 39, 921-929. 
Fleming, J.S. and Courtney, B.E.(1984). The dimensionality of self-esteem: II. Hierarchical facet model for revised measurement scales. Journal of Personality and social Psychology, 46, 404-421.

Fox, K.R.(1988a). The child's perspective in physical education part 5: The self-esteem complex. British Journal of Physical Education, 19, 247-252.

Fox, K.R. (1988b). The self-esteem complex and youth fitness. Quest, $40,230-246$.

Fox, K.R. and Corbin, C.B.(1989). The physical selfperception profile: Development and preliminary validation. Journal of Sport and Exercise Psychology, $11,408-430$.

Fox, K.R., Corbin, C.B., and Couldry, W.H. (1985). Female physical estimation and attraction to physical activity. Journal of Sport Psychology, 7, 125-136.

Gale, J.B., Eckhoff, W.T., Mogel, S.F., and Rodnick, J.E.(1984). Factors related to adherence to an exercise program for healthy adults. Medicine and science in Sports and Exercise, 16, 544-549.

Gecas, V. and Mortimer, J.T.(1987). Stability and change in the self-concept from adolescence to adulthood. In $T$. Honess and K. Yardley(Eds.). Self and identity: Perspectives across the lifespan (pp. 265-286). New York: Routledge and Kegan Paul.

Guilford, J.P. and Fruchter, B. (1973). Fundamental statistics in psychology and education. New York: McGraw-Hill Book Company.

Harter, S.(1982). The perceived competence scale for children. Child Development, 53, 87-97.

Harter, S.(1983). Developmental perspectives on the selfesteem. In E.M. Hetherington(Ed.), P.H. Mussen(Series Ed.), Handbook of child psychology (Vol. 4): Socialization, personality, and social development (pp. 275-385). New York: Wiley.

Harter, S.(1986). Process underlying the construction, maintenance, and enhancement of the self-concept in children. In J. Suls and A.G. Greenwald(Eds.), Psychological perspectives on the self(Vol. 3) (pp. 137181). Hillsdale, New Jersey: Lawrence Erlbaum Associates. 
Horn, J.L.(1965). A rationale and test for the number of factors in factor analysis. Psychometrika, 30, 179-185.

Leonardson, G.R.(1977) . Relationship between self-concept and perceived physical fitness. Perceptual and Motor Skills, 44,62 .

Leonardson, G.R. and Gargiulo, R.M.(1978). Self-perception and physical fitness. Perceptual and Motor skills, 46 , 338 .

Marsh, H.W. (1987). The hierarchical structure of self-concept and the application of hierarchical confirmatory factor analysis. Journal of Educational Measurement, 24, 1739.

Marsh, H.W. and Shavelson, R.(1985). Self-concept: Its multifaceted, hierarchical structure. Educational Psychologist, 20, 107-123.

Neale, D.C., Sonstroem, R.J. and Metz, K.F.(1969). Physical fitness, self-esteem, and attitudes toward physical activity. The Research Quarterly, 40, 743-749.

Rosenberg, M. (1965). Society and the adolescent self-image. Princeton, NJ: Princeton University Press.

Rosenberg, M.(1979). Conceiving the self. New York: Basic Books, Inc.

Rosenberg, M. and Kaplan, H.B.(Eds.).(1982) . Social psychology of the self-concept. Arlington Heights, IL: Harlan Davidson, Inc.

Shavelson, R.J. and Bolus, R.(1982). Self-concept: The interplay of theory and methods. Journal of Educational Psychology, 74, 3-17.

Shavelson, R.J., Hubner J.J. and Stanton, G.C.(1976). Selfconcept: Validation of construct interpretations. Review of Educational Research, 46, 407-441.

Sonstroem, R.J.(1974). Attitude testing examing certain psychological correlates of physical activity. The Research Quarterly, 45, 93-103.

Sonstroem, R.J.(1976). The validity of self-perceptions regarding physical and athletic ability. Medicine and Science in Sports, 8, 126-132. 
Sonstroem, R.J.(1978). Physical estimation and attraction scales: Rationale and research. Medicine and science in Sports, 10, 97-102.

Sonstroem, R.J.(1982). Exercise and self-esteem: Recommendations for expository research. Quest, 33, 124-139.

Sonstroem, R.J.(1984). Exercise and self-esteem. In R. Terjung(Ed.). Exercise and Sport Sciences Reviews, 12, $123-155$.

Sonstroem, R.J. and Morgan, W.P.(1989). Exercise and selfesteem: Rationale and model. Medicine and Science in Sports and Exercise, 21, 329-337.

Thornton, B., Ryckman, R.M., Robbins, M.A., Donolli, J. and Biser, G. (1987). Relationship between perceived physical ability and indices of actual physical fitness. Journal of Sport Psychology, 9, 295-300.

Velicer, W.F.(1976). Determining the number of components from the matrix of partial correlations. Psychometrika, $41,321-327$.

Young, M.L.(1985). Estimation of fitness and physical ability, physical performance, and self-concept among adolescent females. Journal of Sports Medicine, 25, 144-150.

Zwick, W.R. and Velicer, W.F.(1985). A comparison of five rules for determining the number of components in data sets. Unpublished manuscript. (not seen) 